\title{
BMJ Open Myocardial infarction in the Wisconsin Longitudinal Study: the interaction among environmental, health, social, behavioural and genetic factors
}

Tina K Gonzales, ${ }^{1}$ James A Yonker, ${ }^{1}$ Vicky Chang, ${ }^{1}$ Carol L Roan, ${ }^{1}$ Pamela Herd, ${ }^{1,2}$ Craig S Atwood ${ }^{3,4,5}$

To cite: Gonzales TK, Yonker JA, Chang V, et al. Myocardial infarction in the Wisconsin Longitudinal Study: the interaction among environmental, health, social, behavioural and genetic factors. BMJ Open 2017;7: e011529. doi:10.1136/ bmjopen-2016-011529

- Prepublication history and additional material is available. To view please visit the journal (http://dx.doi.org/ 10.1136/bmjopen-2016011529).

Received 11 March 2016 Revised 1 September 2016 Accepted 25 October 2016

CrossMark

For numbered affiliations see end of article.

Correspondence to Dr Craig S Atwood; csa@medicine.wisc.edu

\section{ABSTRACT}

Objectives: This study examined how environmental, health, social, behavioural and genetic factors interact to contribute to myocardial infarction (MI) risk.

Design: Survey data collected by Wisconsin Longitudinal Study (WLS), USA, from 1957 to 2011, including 235 environmental, health, social and behavioural factors, and 77 single-

nucleotide polymorphisms were analysed for association with MI. To identify associations with MI we utilized recursive partitioning and random forest prior to logistic regression and chi-squared analyses. Participants: 6198 WLS participants (2938 men; 3260 women) who (1) had a Ml before 72 years and (2) had a MI between 65 and 72 years.

Results: In men, stroke (LR OR: $5.01,95 \% \mathrm{Cl} 3.36$ to 7.48), high cholesterol (3.29, 2.59 to 4.18), diabetes (3.24, 2.53 to 4.15$)$ and high blood pressure (2.39, 1.92 to 2.96 ) were significantly associated with MI up to 72 years of age. For those with high cholesterol, the interaction of smoking and lower alcohol consumption increased prevalence from $23 \%$ to $41 \%$, with exposure to dangerous working conditions, a factor not previously linked with MI, further increasing prevalence to $50 \%$. Conversely, MI was reported in $<2.5 \%$ of men with normal cholesterol and no history of diabetes or depression. Only stroke $(4.08,2.17$ to 7.65$)$ and diabetes $(2.71,1.81$ to 4.04$)$ by 65 remained significantly associated with Ml for men after age 65 . For women, diabetes (5.62, 4.08 to 7.75$)$, high blood pressure (3.21, 2.34 to 4.39$)$, high cholesterol (2.03, 1.38 to 3.00 ) and dissatisfaction with their financial situation $(4.00,1.94$ to 8.27$)$ were significantly associated with MI up to 72 years of age. Conversely, often engaging in physical activity alone $(0.53,0.32$ to $0.89)$ or with others $(0.34,0.21$ to 0.57$)$ was associated with the largest reduction in odds of MI. Being non-diabetic with normal blood pressure and engaging in physical activity often lowered prevalence of MI to $0.2 \%$. Only diabetes by $65(4.25,2.50$ to 7.24 ) and being exposed to dangerous work conditions at $54(2.24,1.36$ to 3.69$)$ remained significantly associated with MI for women after age 65 , while still menstruating at $54(0.46,0.23$ to 0.91$)$ was associated with reduced odds of MI.

\section{Strengths and limitations of this study}

- 54-year-long longitudinal survey study (Wisconsin Longitudinal Study, WLS).

- Large number of participants with high response rates.

- Large breadth of factors, including environmental, health, social, behavioural and genetic.

- Genetic data used in this study were limited due to prior selection of single-nucleotide polymorphisms by WLS.

- WLS participants are almost exclusively middleclass to upper-middle-class, non-Hispanic whites from Wisconsin, therefore social-factor homogeneities reduce generalisability.

Conclusions: Together these results indicate important differences in factors associated with $\mathrm{Ml}$ between the sexes, that combinations of factors greatly influence the likelihood of $\mathrm{MI}$, that $\mathrm{MI}$-associated factors change and associations weaken after 65 years of age in both sexes, and that the limited genotypes assessed were secondary to environmental, health, social and behavioral factors.

\section{INTRODUCTION}

Heart disease impacts $\sim 26.6$ million US adults and is the leading cause of death among men and women in the USA, accounting for $25 \%$ of deaths $(\sim 600000$ people) annually. ${ }^{1}{ }^{2}$ An estimated 935000 people in the USA suffer from a myocardial infarction (MI) every year. ${ }^{3}$

MI is a symptom of advanced or severe heart disease, ${ }^{4-6}$ and the major modifiable risk factors for MI include high blood pressure, ${ }^{3} 78$ high blood cholesterol, ${ }^{9-13}$ diabetes (mellitus), ${ }^{14-16}$ smoking/tobacco use, ${ }^{17-21}$ obesity and being overweight, ${ }^{22-27}$ poor nutrition/ diet, $^{28-36}$ physical inactivity ${ }^{37-41}$ and (no or excessive) alcohol use. ${ }^{42-47}$ Stress has also been shown to be an important (modifiable) risk 
factor for MI. ${ }^{48-51}$ The major non-modifiable risk factors for MI include sex, ${ }^{52-57}$ age, $^{3} 5859$ family history ${ }^{60-63}$ and race. ${ }^{1364}$ However, not all individuals with these risk factors experience a MI. Thus, it is likely that combinations of these risk factors, or as yet unknown risk factors, are important in the aetiology of the disease.

Other non-modifiable risk factors include genetic polymorphisms such as those identified in $A P O E$ (apolipoprotein E) ${ }^{65} \quad 66$ CETP (cholesteryl ester transfer protein) ${ }^{67-69}$ and $C D K N 2 A / 2 B$ (cyclin-dependent kinase $2 \mathrm{~A} / 2 \mathrm{~B}),{ }^{70}$ but there is no consensus about which gene (s) are most predictive of MI. In addition, there are few large-scale studies that have looked at the interactions between genetic and environmental, health, social and behavioural factors that predict MI.

Research has shown that risk factors for heart disease and MI are moderated by sex and age, and the interaction of risk factors with heart disease and MI affects men and women differently at different ages throughout their lives. ${ }^{53-55} 5771$ For example, women are more likely than men to die within 1 year of experiencing an MI when younger, ${ }^{72}{ }^{73}$ but in general first experience MI later in life than do men, ${ }^{55}$ although men are more likely to experience MI overall. ${ }^{3}$ Identification of sex-specific factors associated with MI and how those associations change over time is important for predicting disease risk throughout life.

In this study, we examined how the interaction among environmental, health, social, behavioural and genetic factors associates with MI, with the goal of determining (1) differences in factors associated with MI between men and women, with a focus on the interaction among factors; (2) how interactions among these factors affect MI occurrence; (3) how factors associated with MI change over a person's lifetime, again with a focus on the interaction among factors and (4) what combined factors are associated with reduced occurrence of MI, even in the presence of other known risk factors.

\section{METHODS}

\section{Study participants and WLS survey data}

The Wisconsin Longitudinal Study (WLS) is a 54-year-long survey study on the lives of a cohort of 1957 Wisconsin high-school graduates. The original cohort of participants was made up of 10317 men and women, randomly selected from those graduating from a Wisconsin high school in 1957. Self-reported survey data were collected from WLS graduate participants in 1957, 1964, 1975, 1993, 2004 and 2011. Data from each of the aforementioned survey rounds were included in this study, with many of the selected variables representing the same questions asked at multiple time points (WLS survey rounds). In addition, DNA saliva samples were provided by a subset of the WLS (4562 graduates) and 77 single-nucleotide polymorphisms (SNPs) were genotyped for each of these participants in 2009, providing genetic data for a subset of the WLS as well. Additional information about the WLS survey data and participants can be found elsewhere ${ }^{74}$ (http:// www.ssc.wisc.edu/wlsresearch/).
The WLS has enjoyed high response rates across multiple survey waves. The data for the current analyses come primarily from the 1993, 2004, and 2011 survey waves when the cohort was 53, 64 and 71 years old, respectively. In 1993, 8493 cohort members participated in the telephone survey, 588 refused to participate, 587 were deceased and 649 were unfielded for either administrative reasons or permanent disability. In 2004, 7265 cohort members participated in the telephone survey, 956 refused, 1287 were deceased and 809 were unfielded. Finally, for the 2011 in-home interview, 5968 cohort members participated in the survey, 1088 refused, 1587 were deceased and 1674 were unfielded (see online supplementary table S1). Among those not deceased, response rates for these survey waves were $87 \%, 80 \%$ and $60 \%$, respectively. Also excluding unfielded cases from the denominator brings the response rates to $94 \%, 88 \%$ and $85 \%$.

\section{Study questions and dependent variables}

This study examined factors potentially associated with MI using environmental, health, social, behavioural and genetic data available through the WLS. Two sets of data were analysed based on survey years of data collection, looking at anyone who reported a MI up to 72 years of age and only those who reported a MI between 65 and 72 years. We did this for two reasons: (1) to examine MI up to 72 years and what factors would be associated with this group regardless of when their MI occurred; and (2) an analysis of factors that occurred only before a MI. Owing to the timing of the survey years, this allowed us to look at factors associated with MI at any point in one's lifetime (up to 72 years), versus factors associated with a MI in 'older age' (65-72 years).

In order to create our two dependent variables, we compiled data from the 2004 and 2011 WLS surveys including National Death Index (NDI) data. The first dependent variable, 'MI by 72 years of age', was coded as 'yes' if a participant reported experiencing a MI in 2004 or 2011 or died of MI according to the NDI (ICD-9 or ICD-10 codes; note: NDI data were collected by the WLS only up to 2006 at the time of the current study), thereby including anyone who reported having a MI to the WLS. The dependent variable was coded 'no' only if no previous MIs were reported and the participant reported no MIs in 2011. This resulted in MI data for 6198 graduates, with 776 participants coded as 'yes' and 5422 coded as 'no' for the given variable. Additionally, this dependent variable was linked to a data set which included independent variables from all WLS survey years, 1957-2011. Characteristics of the WLS participants included in this study population are shown in table 1. The second dependent variable, 'MI between 65 and 72 years of age', was coded similarly to the first, but included only those participants who reported no MIs by 2004, thereby excluding individuals who had a MI before 65 years of age. This dependent variable was coded as 'yes' if the participant reported having a MI 
Table 1 Participant characteristics for those included in the current study

\begin{tabular}{|c|c|c|c|}
\hline Characteristic, survey year collected & $\begin{array}{l}\text { Total population: } \\
\mathrm{n}(\%) \text { or mean }( \pm \text { SD) }\end{array}$ & $\begin{array}{l}\text { Males: } \\
\mathrm{n}(\%) \text { or mean }( \pm \text { SD) }\end{array}$ & $\begin{array}{l}\text { Females: } \\
\mathrm{n}(\%) \text { or mean ( } \pm \text { SD) }\end{array}$ \\
\hline 'MI by 72 years of age' DV & 6198 & $2938(47.4 \%)$ & $3260(52.6 \%)$ \\
\hline Included in DV 'MI Between 65 and 72' & $5321(85.9 \%)$ & $2404(81.8 \%)$ & 2917 (89.5\%) \\
\hline Ever experienced MI & $776(12.5 \%)$ & $533(18.1 \%)$ & $243(7.5 \%)^{\star \star *}$ \\
\hline IQ Score (Henmon-Nelson), 1957 & $102.1(14.77)$ & $101.9(15.22)$ & $102.2(14.37)$ \\
\hline Years of education ${ }^{\ddagger}, 1993$ & $13.75(2.33)$ & $14.14(2.55)$ & $13.41(2.05)^{\star \star \star}$ \\
\hline Age at interview, 2004 & $64.33(0.70)$ & $64.40(0.73)$ & $64.27(0.67)^{\star \star \star}$ \\
\hline Married, 2004 & $4652(78.6 \%)$ & $2368(85.4 \%)$ & $2284(72.7 \%)^{\star \star *}$ \\
\hline Total household income, 2004 & $\$ 30619(\$ 7)$ & $\$ 42364(\$ 6)$ & $\$ 22961(\$ 8)^{\star \star *}$ \\
\hline Smoker, 2004 & $613(11.6 \%)$ & $296(12.0 \%)$ & $317(11.2 \%)$ \\
\hline Alcohol (days/month), 2004 & $7.57(9.67)$ & $9.47(10.50)$ & $5.89(8.54)^{\star \star \star}$ \\
\hline
\end{tabular}

between 2004 and 2011 (in 2011) or died of acute MI after 2004 and was coded as 'no' if the participant reported no MIs in 2011. This resulted in MI data for 5321 graduates, with 213 participants coded as 'yes' and 5108 coded as 'no'. This dependent variable was linked to a data set which included only independent variables collected during the 2004 survey year or earlier. Information about specific WLS variables used to create the two dependent variables for the current study is provided in online supplementary information 1 .

\section{Environmental, health, social and behavioural data}

From the data generated by the WLS, official release V.13.01, we analysed 235 environmental, health, social and behavioural variables against MI data for WLS participants included in this study. These included descriptive, family, spouse, children, personality, medical history, family's medical history, general health and weight, exercise, sleep, smoking, alcohol consumption, social, work-related, socioeconomic, life satisfaction, stress-related and coping, stressful life events, summary psychological and personality variables collected by the WLS (see online supplementary table S2). We analysed an additional 26 variables in all female-specific analyses, which included variables related to menstruation, menopause, reproductive surgeries and hormone replacement therapies.

One variable, 'Summary Score Anger Index, 2004', was updated by the WLS during the course of this study, in July 2014. Therefore, for this variable the updated version 13.02 data were substituted for the version 13.01 data for all analyses conducted. Additionally, in the WLS surveys there were some questions that were asked of only a subset of the WLS participants, specifically, the alcohol-related and depression-related questions were only asked of a $79 \%$ random subset of the WLS.

\section{SNP genotyping data}

Of the 4562 graduates who provided DNA saliva samples to the WLS, 4012 also answered the MI questions and were therefore included in the SNP analyses for this study. A total of 77 SNPs were genotyped for each of these participants in 2009, as described in Roetker et $a l^{76}$ This study also included five additional genetic variables based on $A P O E$, because of its known association with cardiovascular

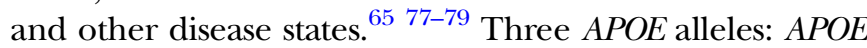
$\varepsilon 2, A P O E \varepsilon 3$ and $A P O E \varepsilon 4$, determined by the SNPs rs429358 and rs7412 were used to determine $A P O E$ status. $^{80} 81$ From this, we created five variables, allele APOE4 4 , allele $A P O E 2 \pm$, genotype E4/E4, genotype E2/E2 and specific $A P O E$ genotype (see online supplementary table 2).

\section{Statistical analyses}

This study looked for independent as well as interactive effects of environmental, health, social, behavioural and genetic variables for the 6198 and 5321 WLS graduates for which data were available for our two dependent variables (MI by 72 years and MI between 65 and 72), respectively. Of these, 4012 and 3684 respectively, also provided genetic data which was analysed for independent as well as interactive effects separately and in combination with environmental, health, social and behavioural data, in order to identify the combination of factors most associated with MI. In order to address possible collinearity of covariates measured in multiple survey rounds, we first completed a recursive partitioning (RP) and random forest (RF) analysis in order to reduce the number of variables analysed and then ran independent logistic regression (LR) analysis for each independent variable identified, rather than a multiple regression analysis of all independent variables. A similar strategy, using machine-learning methodologies to identify associations followed by LR analysis of individual factors, has been used in prior studies. ${ }^{76}$

\section{Recursive partitioning}

RP was used to create classification trees to determine main factor and interactive effects associated with MI 
using environmental, health, social, behavioural and genetic variables, individually and combined, in order to assess whether MI is better explained by our environment, our genetics or a combination of both. All RP analyses were completed using the R program, V.2.15.2 (R: A language and environment for statistical computing (program), Vienna, Austria: R Foundation for Statistical Computing, 2008) with package 'rpart' (rpart: Recursive Partitioning (program), $\mathrm{R}$ package version 3.1-55. version, 2012), based on Breiman's classification and regression trees algorithm. ${ }^{82}$ The usesurrogate parameter was set to 0 , maxcompete was set to 0 , maxsurrogate was set to 0 and the complexity parameter was set to 0.01 . A 10 -fold cross-validation procedure was used to determine how far back to prune the trees. Odds ratios (ORs) and 95\% confidence intervals (CIs) were calculated using MedCalc (http://www.medcalc.org/calc/ odds_ratio.php; calculations according to Altman ${ }^{83}$ ). When zeros appeared in the terminal nodes of the RP trees, MedCalc used an ad hoc method to determine estimates of OR. ${ }^{8485}$

\section{Random forest}

$\mathrm{RF}^{86-89}$ was used in our association analyses ${ }^{90-93}$ and was conducted using the 'randomForest' package ${ }^{94}$ (Online $\mathrm{R}$ documentation for the package 'randomForest' (program), 4.6-10 version, 2014) available with the $\mathrm{R}$ program. We chose to use 'margin measure' or mean decrease in accuracy to determine variable importance. ${ }^{95} 96$ Missing values were imputed for independent variables using the 'na.roughfix' command, which imputes missing values using either the median value for numeric variables, or the most frequent level for factor variables. Using imputed values with the 'rfImpute' command for missing data was considered here, but the bias that was noted in preliminary analyses was considered too great. Three trials of RF were conducted for each 'variable importance' measure, to determine the replicability of the results, in large part because of the randomness associated with this particular test. Using the dependent variable 'MI by 72 years of age' and associated data set, the 'mtry' parameter was set to 34 for men and 36 for women, based on the lowest out-of-bag (OOB) estimate of error rate of $12.25 \%$ and $5.09 \%$, respectively. Using the dependent variable 'MI between 65 and 72 years of age' and associated data set, the 'mtry' parameter was set to 30 for men and 32 for women, based on the OOB estimate of error rate of $5.87 \%$ and $2.47 \%$, respectively. The number of trees in the forest, the 'ntree' parameter, was set to 5000 for men and women in both analyses.

\section{LR and $\chi^{2}$}

Single-factor associations with MI were determined for all environmental, health, social, behavioural and genetic variables that appeared in either the RP tree(s) or the RF list(s) of 'important' variables generated for each of the dependent variable analyses, using a LR model and $\chi^{2}$ test with $\mathrm{R}$. For those cases where the sample size (one or more categories) was too small for a $\chi^{2}$ test $(\mathrm{n}<5)$, Fisher's Exact test was used to calculate significance. When necessary, Fisher's Exact test $p$ values were obtained using Monte Carlo simulation. LR ORs were determined by exponentiating the coefficients of the regression models using the $\mathrm{R}$ program. All $\mathrm{p}$ values generated from these tests were adjusted for multiple testing using a q-value adjustment, with the $\mathrm{R}$ program V.2.15.2, package 'qvalue' ${ }^{97}$ (qvalue: Q-value estimation for false discovery rate control (program), $\mathrm{R}$ package version 1.32.0, 2014) which has been shown to be less stringent than the Bonferroni adjustment. All significance findings from LR and $\chi^{2}$ (or Fisher's Exact test) reported herein refer to these adjusted values.

\section{Inclusion and Logical Bounding}

Only those factors that were identified by at least three of the four analyses employed and increased or decreased odds of MI by at least $40 \%$ were considered significantly associated with MI in this study and included herein. Furthermore, in order to address any bias that may have been created due to missing data (non-response) in this study, we performed a 'logical bounding' procedure in which we logically filled in missing data points in our data set, first with all participants who were not included due to missing values coded as 'yes' for MI and then as 'no' for MI. We then reran our LR analyses in order to see if our 'overall' factors associated with MI remained statistically significant and thereby determine if our results were robust. All $\mathrm{p}$ values generated from this logical bounding were also adjusted for multiple testing using q-value adjustment.

\section{RESULTS}

To assess changes in MI-associated factors over a person's lifetime, separate analyses were performed on individuals who ever had a MI up to 72 years of age compared to those who had a MI between 65 and 72 years of age (see the 'Methods' section). Participants included in the 'MI by 72 years of age' dependent variable were $47.4 \%$ men, had an average IQ of 102.1 with an average 13.75 years of regular education. At the time of the 2004 interview, the average age of participants was 64.3 years, $78.6 \%$ were married, with an average total household income of US\$30,619. $11.6 \%$ of participants were smokers, consumed alcohol on average 7.6 days/month, and $12.5 \%$ have ever reported a MI to the WLS (see table 1 ). Of these participants, $85.9 \%$ were also included in the 'MI between 65 and 72 years of age' dependent variable. Men in the WLS were significantly more likely to experience MI than were women, to have more education, to be married, to have a higher household income and to drink alcohol more days per month than women in the WLS (table 1; based on $t$-test or equal proportions test). All analyses identified sex as the factor most associated with MI (see online supplementary 
information 2), therefore men and women were analysed separately throughout this study. Note to readers: we reported results in terms of MI 'by 72' years and MI 'between 65 and 72' years because the majority of participants were 65 or younger during the 2004 survey and 72 or younger during the 2011 survey.

\section{Men}

MI up to age 72

\section{Interactive effects}

RP analysis indicated that $18.1 \%$ of men in this study reported a MI by age 72 . High cholesterol by 65 years old was the most significant factor associated with MI among men according to RP (figure 1), with a prevalence of $23.1 \%$ versus $8.4 \%$ (OR $3.29,95 \%$ CI 2.59 to 4.18). For men with normal cholesterol at 65 , the interactions among factors associated with the largest increase in MI prevalence were being diabetic by 65 , summary score for openness at 65 and genotype for the CYP11B2 gene (rs1799998 SNP), increasing MI prevalence to $30.6 \%$ versus $0.0 \%$ (20.22, 1.15 to 355.10 ). For men with normal cholesterol who were non-diabetic at 65 , important interactions included their summary score for (psychological) distress/depression at 65 and having high blood pressure by 65 , with MI prevalence at $27.5 \%$ versus $7.5 \%$ (4.66, 1.90 to 11.38$)$. Among those men with a lower summary score for depression, important interactions included having high cholesterol by 72 and lower alcohol consumption at 72 , with MI prevalence at $26.9 \%$ versus $4.4 \%$ (6.89, 2.12 to 22.44$)$.

For men who did have high cholesterol by 65 , important interactions among factors associated with MI include the number of years the participant had smoked by 54 , alcohol consumption at 65 , exposure to dangerous work conditions at 65 and genotype for the FADS2 gene (rs174575 SNP), with MI prevalence at $46.7 \%$ versus $7.1 \%$ (11.38, 1.96 to 66.12$)$. For men who had high cholesterol by 65 , but had smoked fewer years by 54 , important interactions included being diabetic by 65 , the extent to which one agreed that family worries or problems distracted from work at 65 and total years of college completed, with MI prevalence increased to $53.3 \%$ versus $0.0 \%$ (19.34, 1.02-365.26). For the men who did have high cholesterol by 65 , but smoked fewer years by 54 and were non-diabetic at 65 , important interactions among factors included having a biological parent or sibling who had a MI before age 55, the most he ever weighed in pounds by 72 , total household income at 65 and genotype for the IL6 gene (rs1800795 SNP), with MI prevalence at $32.6 \%$ versus $5.3 \%$ (8.69, 1.83 to 41.36 ) (figure 1 ).

\section{Single factor effects}

For men up to 72 years old, the 10 most 'important' factors associated with MI determined using RF were as follows: (1) days/month drinking alcohol, (2) total household income, (3) dissatisfaction with financial situation, (4) alcoholic drinks/month, (5) high blood pressure, (6) number of children, (7) high cholesterol, (8) the frequency that work required physical effort, (9) pack-years smoked and (10) worrying a lot, each at 72 years old (see online supplementary figure 1 for additional 'important' factors associated with MI by RF).

Of the factors that were associated with MI by RP or RF, LR identified having high cholesterol by 65 (3.29, 2.59 to 4.18$)$ and 72 (3.32, 2.50 to 4.42$)$, diabetes by 65 (3.24, 2.53 to 4.15$)$ and $72(2.26,1.78$ to 2.88$)$, stroke by 65 (5.01, 3.36 to 7.48$)$, high blood pressure by 65 (2.39, 1.92 to 2.96$)$ and $72(2.16,1.67$ to 2.79$)$, exposure to dangerous conditions at work at 65 (1.41, 1.11 to 1.79$)$ and having a parent or sibling who had a MI before age $55(1.89,1.43$ to 2.49$)$ as significantly associated with MI for men in this study (table 2A). $\chi^{2}$ also identified these factors as significantly associated with MI.

\section{Overall associations with MI by 72 years of age}

Factors identified by at least three of the analyses employed by this study as associated with MI were compiled in order to determine which factors were most associated with MI in the WLS cohort. For men who had a MI any time up to 72 years of age, the factors associated with MI by all four analyses were having high cholesterol by 65 , having high cholesterol by 72 and being diabetic by 65 , which were all highly significant by LR and $\chi^{2}$ (table 2A). These results are supported by the male RP tree, as having high cholesterol by 65 and being diabetic by 65 were the first and second nodes in that tree (figure 1). The factors that were associated with MI by three of the analyses in this study including $\mathrm{RF}$ were being diabetic by 72 , having had a stroke by 65 and having high blood pressure by 72 , which were all highly significant by LR and $\chi^{2}$. The factors that were associated with MI by three of the analyses including RP were having high blood pressure by 65 , exposure to dangerous conditions at work at 65 and having a parent or sibling who had a MI before age 55, which were all significant by LR and $\chi^{2}$ (table $\left.2 \mathrm{~A}\right)$.

\section{MI between 65 and 72 years of age Interactive effects}

In the second set of analyses, $5.9 \%$ of men reported a MI between 65 and 72 years of age. Days/month drinking alcoholic beverages at 65 years old was the only significant factor identified as associated with MI among men 65-72 according to RP (figure 2), with incidence at $7.7 \%$ among those who drank $<8.5$ days/month versus $2.9 \%$ among those who drank $\geq 8.5$ days/month $(2.77,1.80$ to 4.25$)$.

\section{Single factor effects}

For men between 65 and 72 years of age, the 10 most 'important' factors associated with MI determined using RF were: (1) alcoholic drinks/month at 65 years old, (2) summary score for distress/depression at 54, (3) body mass index at 54, (4) alcoholic drinks/month at 54, (5) summary score for neuroticism at 54, (6) the most ever weighed (by 65), (7) days/month drinking alcohol at 
'MI by 72 Years of Age'

MI Associated Factors for Males

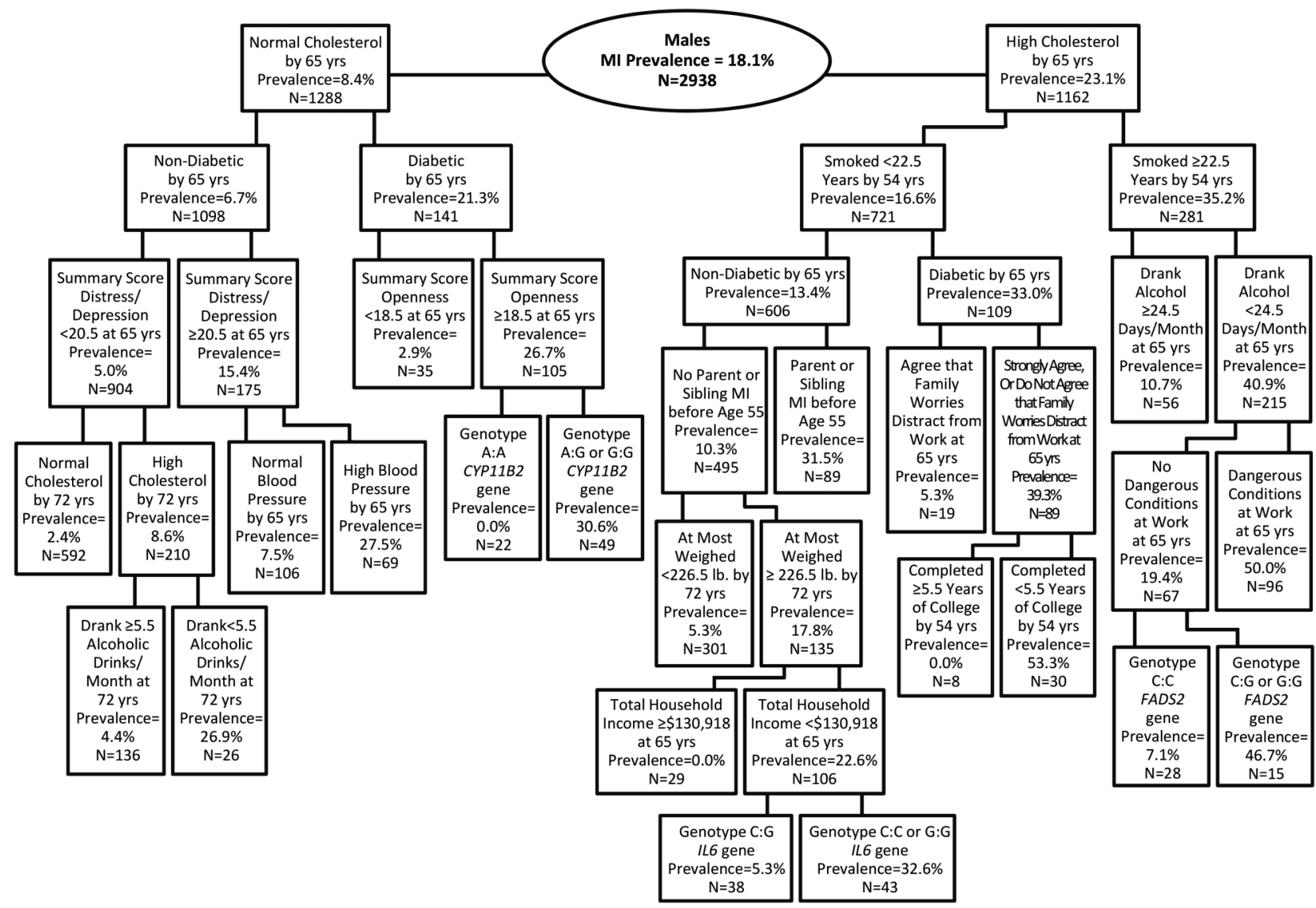

Figure 1 RP tree showing interactions among Ml-associated factors for men who ever had a Ml by 72 years of age in the WLS cohort, with MI prevalence listed at each node in the tree. MI, myocardial infarction; RP, recursive partitioning; WLS, Wisconsin Longitudinal Study.

$65,(8)$ body mass index at 65 , (9) pack-years smoked at 54 and (10) years smoked at 54 (see online supplementary figure 2 for additional 'important' factors associated with MI by RF).

Of the factors that were associated with MI by RP or RF, LR identified having had a stroke by $65(4.08,2.17$ to 7.65$)$ and being diabetic by 65 (2.71, 1.81 to 4.04$)$ as significantly associated with MI for men 65-72 years old (table 2B). $\chi^{2}$ also identified these two factors as significantly associated with MI for men in this age group (table 2B).

\section{Overall associations with MI between 65 and 72 years of age}

For men between 65 and 72 years old, the factors associated with MI by at least three of the four analyses employed by this study were having had a stroke by 65 and being diabetic by 65 , which were highly significant by LR and $\chi^{2}$ and 'important' factors by RF (table $2 \mathrm{~B}$ ).

\section{Women}

MI up to age 72

Interactive effects

$\mathrm{RP}$ analysis indicated that $7.5 \%$ of women in this study reported a MI by age 72. For women, being diabetic by 65 was the most significant factor associated with MI according to RP, with a prevalence of $22.4 \%$ versus $4.9 \%$ (5.62, 4.08 to 7.75 ; figure 3$)$. For the latter group, important interactions among factors associated with MI included high blood pressure by 65 and how often they engaged in light physical activities with others at 67 , with MI prevalence at $3.7 \%$ versus $0.2 \%(18.39,2.49$ to 135.77). And among the women who were non-diabetic, but did have high blood pressure by 65 , important interactions included how many years they had smoked by age 54 , with MI prevalence at $16.6 \%$ versus $5.1 \%$ (3.70, 2.30 to 5.94), and how often the participant blamed themselves when they experienced a difficult or stressful event at 72 years old, with MI prevalence at $11.8 \%$ versus $2.7 \%$ $(4.87,2.25$ to 10.55 ; figure 3$)$.

\section{Single-factor effects}

For women up to 72 years old, the 10 most 'important' factors associated with MI determined using RF were as follows: (1) days/month drinking alcohol at 72, (2) dissatisfaction with financial situation at 72, (3) total household income at 72 , (4) high blood pressure by 72 , (5) worrying a lot at $72,(6)$ alcoholic drinks/month at 72 , (7) being diabetic by 65 , (8) number of children, (9) 
Table 2 Ml-associated factors for men found significant by at least three of the four statistical analyses employed by this study, (A) who ever had an Ml by 72 years of age and (B) who had a Ml between 65 and 72 years of age.

\begin{tabular}{|c|c|c|c|c|c|}
\hline $\begin{array}{l}\text { Factor description } \\
\text { (age at survey year) }\end{array}$ & $\begin{array}{l}\text { MI case/ } \\
\text { non-case } \\
\text { (n) }\end{array}$ & $\begin{array}{l}\text { Random forest } \\
\text { 'important' } \\
\text { variables }\end{array}$ & $\begin{array}{l}\text { Logistic } \\
\text { regression } \\
\text { OR }(95 \% \mathrm{Cl}) \\
\end{array}$ & $\begin{array}{l}\chi^{2} \\
\text { (adjusted } \\
p \text { value) } \\
\end{array}$ & $\begin{array}{l}\text { Recursive } \\
\text { partitioning } \\
\text { (tree nodes) }\end{array}$ \\
\hline \multicolumn{6}{|l|}{ (A) Males, 'MI by 72 years of age' } \\
\hline High cholesterol (by 65 years) & 269/893 & Yes & $3.29(2.59 \text { to } 4.18)^{\star \star \star}$ & $<0.0001^{\mathrm{C}}$ & Present \\
\hline High cholesterol (by 72 years) & $221 / 987$ & Yes & $3.32(2.50 \text { to } 4.42)^{\star \star \star}$ & $<0.0001^{\mathrm{C}}$ & Present \\
\hline Diabetes (by 65 years) & $124 / 254$ & Yes & $3.24(2.53 \text { to } 4.15)^{\star \star \star}$ & $<0.0001^{\mathrm{C}}$ & Present \\
\hline Diabetes (by 72 years) & $122 / 458$ & Yes & $2.26(1.78 \text { to } 2.88)^{\star \star \star}$ & $<0.0001^{\mathrm{C}}$ & \\
\hline Stroke (by 65 years) & $48 / 56$ & Yes & $5.01(3.36 \text { to } 7.48)^{\star \star \star}$ & $<0.0001^{\mathrm{C}}$ & \\
\hline High blood pressure (by 72 years) & $269 / 1428$ & Yes & $2.16(1.67 \text { to } 2.79)^{\star \star \star}$ & $<0.0001^{\mathrm{C}}$ & \\
\hline High blood pressure (by 65 years) & $283 / 1023$ & & $2.39(1.92 \text { to } 2.96)^{\star \star \star}$ & $<0.0001^{\mathrm{C}}$ & Present \\
\hline $\begin{array}{l}\text { Exposed to dangerous conditions at } \\
\text { work (by } 65 \text { years) }\end{array}$ & $174 / 784$ & & $1.41(1.11 \text { to } 1.79)^{\star \star}$ & $0.0080^{C}$ & Present \\
\hline $\begin{array}{l}\text { Parent or sibling had a MI before age } \\
55 \text { (by } 65 \text { years) }\end{array}$ & $82 / 267$ & & $1.89(1.43 \text { to } 2.49)^{\star \star \star}$ & $<0.0001^{\mathrm{C}}$ & Present \\
\hline \multicolumn{6}{|c|}{ (B) Males, 'MI between 65 and 72 years of age' } \\
\hline Stroke (by 65 years) & $13 / 55$ & Yes & $4.08(2.17 \text { to } 7.65)^{\star \star \star}$ & $0.0002^{F}$ & \\
\hline Diabetes (by 65 years) & $36 / 254$ & Yes & $2.71(1.81 \text { to } 4.04)^{\star \star \star}$ & $<0.0001^{\mathrm{C}}$ & \\
\hline
\end{tabular}

\section{'MI Between 65-72 Years of Age' MI Associated Factors for Males}

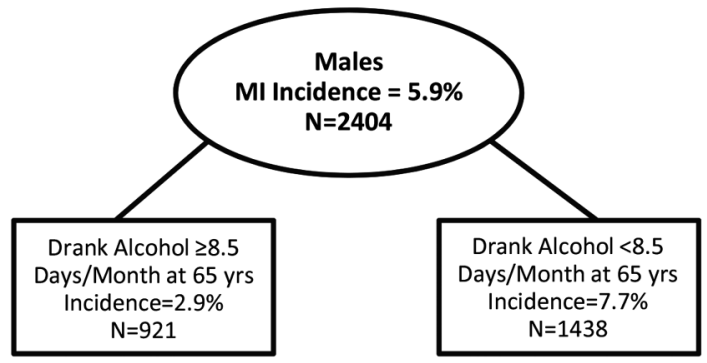

Figure $2 \mathrm{RP}$ tree showing the only factor associated with $\mathrm{Ml}$ by RP for men between 65 and 72 years of age in the WLS cohort, with $\mathrm{Ml}$ incidence listed at the terminal nodes of the tree. MI, myocardial infarction; $\mathrm{RP}$, recursive partitioning; WLS, Wisconsin Longitudinal Study.

body mass index at 72 and (10) the most ever weighed (by 72) (see online supplementary figure 3 for additional 'important' factors associated with MI by RF).

Of the factors that were associated with MI by RP or RF, LR identified being diabetic by 54 (6.93, 4.18 to 11.49), 65 (5.62, 4.08 to 7.75$)$ and $72(4.24,3.04$ to 5.91$)$, high cholesterol by $72(2.03,1.38$ to 3.00$)$ being unmarried at $72(1.59,1.16$ to 2.18$)$, dissatisfaction with financial situation at 72 ( (not at all) 4.00, 1.94 to 8.27 ; (somewhat) $2.02,1.31$ to 3.12 ; multiple coefficients significant by LR), not often engaging in vigorous physical activity alone at 67 (0.53, 0.32 to 0.89$)$, high blood pressure at $65(3.21,2.34$ to 4.39$)$ and 72 (3.37, 2.23 to 5.09 ) and not often engaging in light physical activity with others at $67(0.34,0.21$ to 0.57$)$ as significantly associated with MI for women in this study (table $3 \mathrm{~A}) \cdot \chi^{2}$ also identified these factors as significantly associated with MI (table $3 \mathrm{~A})$.

\section{Overall associations with MI by 72 years of age}

For women who reported a MI any time up to 72 years of age, the factor associated with MI by all four analyses was being diabetic by 65 years old, which was highly significant by LR and $\chi^{2}$ (table $3 \mathrm{~A}$ ), and was the most associated factor according to the female RP tree (figure 3). The factors associated with MI by three of the analyses in this study including RF were being diabetic by 54 and 72 , having high cholesterol by 72 , being unmarried at 72 , dissatisfaction with financial situation at 72, not often engaging in vigorous physical activity alone at 67 and having high blood pressure at 72, which were all significant by LR and $\chi^{2}$. The factors associated with MI in women by three of the analyses in this study including RP were having high blood pressure by 65 and not often engaging in light physical activity with others at 67, which were both highly significant by LR and $\chi^{2}$ (table 3A).

\section{MI between 65 and 72 years of age \\ Interactive effects}

In the second set of analyses, $2.5 \%$ of women reported a MI between 65 and 72 years of age. Being diabetic by 65 years old was again the most significant factor associated with MI among women in this age bracket according to RP (figure 4), with a MI incidence of $7.8 \%$ versus $2.0 \%(4.25,2.50$ to 7.24$)$. For women who were diabetic 
'MI by 72 Years of Age'

MI Associated Factors for Females

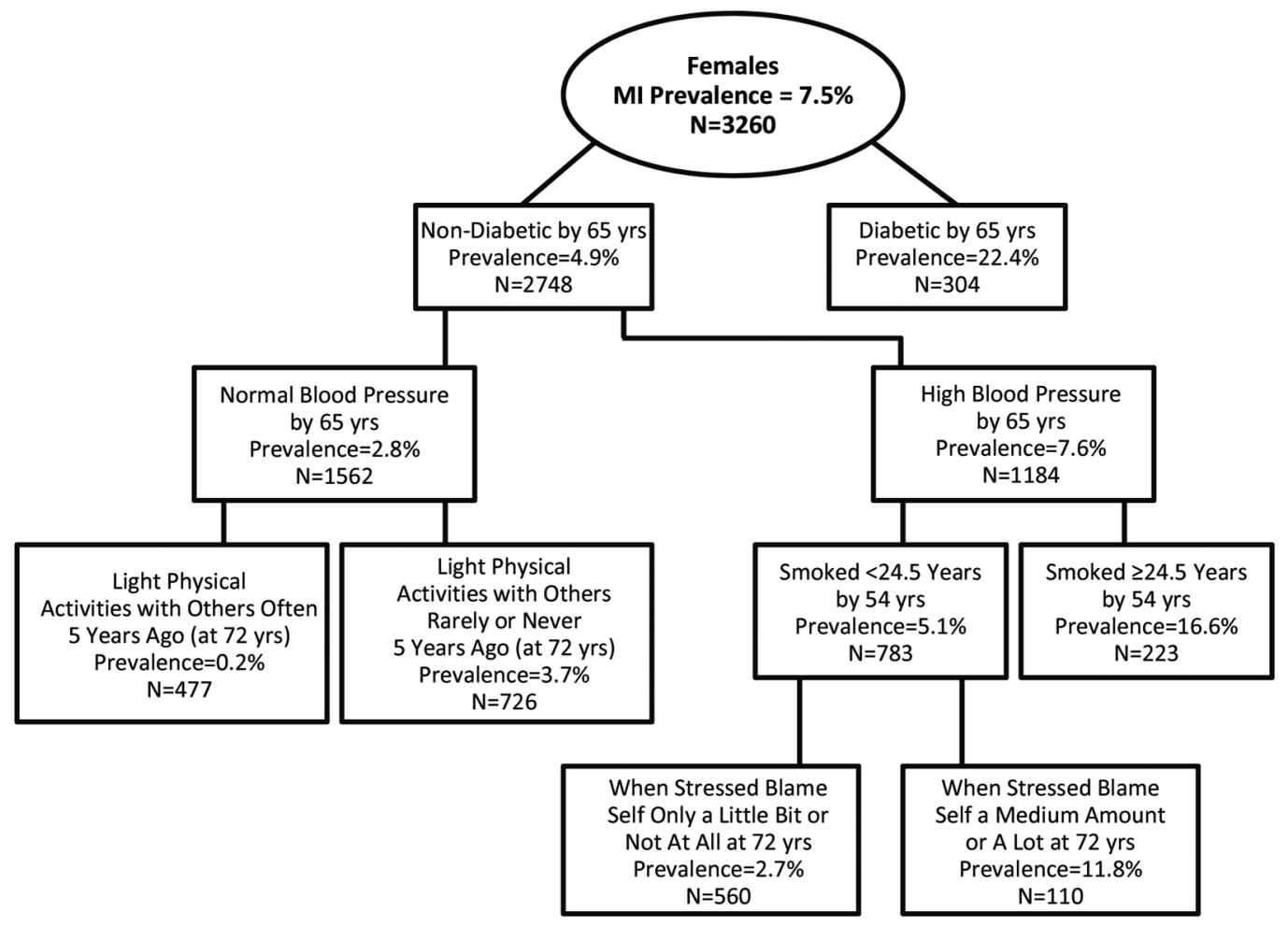

Figure 3 RP tree showing interactions among Ml-associated factors for women who ever had a Ml by 72 years of age in the WLS cohort, with MI prevalence listed at each node in the tree. MI, myocardial infarction; RP, recursive partitioning; WLS, Wisconsin Longitudinal Study.

by 65 years old, important interactions among factors associated with MI included their summary score for agreeableness at 65 and not having had a menstrual period in the last 12 months by 54 years of age, increasing MI incidence to $14.0 \%$ versus $0.0 \%(13.58,0.79$ to 233.29). For those women who were non-diabetic at 65 , important interactions included IQ genotype for the INHBB gene SNP (rs11902591) and how often their work required physical effort at 54 , with $\mathrm{MI}$ incidence at $25.0 \%$ versus $0.0 \%$ (37.95, 1.81 to 795.67$)$. And among those women with a lower IQ score, important interactions included their summary score for extraversion at 54 , how often they engaged in light physical activities alone at 65 , the number of alcoholic drinks consumed per month at 65 , body mass index at 65 , genotype for the A2M gene (rs669 SNP), how often they worked under the pressure of time at 54 and the age at which they had last menstruated, with MI incidence increasing to $13.8 \%$ versus $0.0 \%$ (12.42, 0.72 to 215.47 ) (figure 4 ).

\section{Single factor effects}

For women between 65 and 72 years of age, the 10 most 'important' factors associated with MI determined by RF were as follows: (1) alcoholic drinks/month at 65 years old, (2) summary score for distress/depression at 65, (3) being diabetic by $65,(4)$ body mass index at $65,(5)$ the most ever weighed (by 65), (6) days/month drinking alcohol at 54, (7) days/month drinking alcohol at 65, (8) drinks/day on days when drank alcohol at 65, (9) age when had surgery to remove uterus and/or ovaries and (10) summary score for distress/depression at 54 (see online supplementary figure 4 for additional 'important' factors associated with MI by RF).

Of the factors associated with MI by RP or RF, LR identified being diabetic by $65(4.25,2.50$ to 7.24$)$, exposure to dangerous work conditions at 54 (2.24, 1.36 to 3.69$)$ and having had a menstrual period in the last 12 months at $54(0.46,0.23-0.91)$ as significantly associated with MI for women between 65 and 72 years of age (table 3B). $\chi^{2}$ also identified these factors as significantly associated with MI for women in this age group (table 3B).

\section{Overall associations with $\mathrm{MI}$ between 65 and 72 years of age}

For women between 65 and 72 years old, the factor associated with MI by all four analyses was being diabetic by 65 , which was highly significant by LR and $\chi^{2}$ (table $3 \mathrm{~B}$ ), and was the factor most associated with MI according to the female RP tree for this age group (figure 4). The factors associated with MI by at least three of the analyses employed in this study were exposure to dangerous 
Table $3 \mathrm{Ml}$-associated factors for woman found significant by at least three of the four statistical analyses employed by this study, (A) who ever had an MI by 72 years of age and (B) who had a Ml between 65 and 72 years of age.

\section{Factor description (age at survey year)}

\begin{tabular}{|c|c|c|}
\hline $\begin{array}{l}\text { Ml case/ } \\
\text { non-case } \\
\text { (n) }\end{array}$ & $\begin{array}{l}\text { Random forest } \\
\text { 'important' } \\
\text { variables }\end{array}$ & $\begin{array}{l}\text { Logistic regression } \\
\text { OR }(95 \% \mathrm{Cl})\end{array}$ \\
\hline
\end{tabular}

(A) Females, 'Ml by 72 years of age'

Diabetes (by 65 years)

Diabetes (by 54 years)

Diabetes (by 72 years)

High cholesterol (by 72 years)

Unmarried (by 72 years)

Financial situation - 'not at all' satisfied (by 72 years) ${ }^{\dagger}$

Financial situation - 'somewhat' satisfied (by 72 years) ${ }^{\dagger}$

Vigorous physical activity alone 5 years ago - often

(by 72 years)

High blood pressure (by 72 years)

High blood pressure (by 65 years)

Light physical activity with others 5 years ago - often 23/876

$68 / 236 \quad$ Yes

\section{$24 / 55$}

$64 / 406$

$89 / 1354$

$77 / 1079$

$11 / 73$

$67 / 879$

$21 / 639$

Yes

Yes
Yes

Yes
Yes

Yes

Yes
Yes

Yes

Yes

Yes

$145 / 1260$ OR (95\% Cl)

$\begin{array}{ll}\chi^{2} & \text { Recursive } \\ \text { (adjusted } & \text { partitioning } \\ \text { p value) } & \text { (tree nodes) }\end{array}$

2 years)

(B) Females, 'MI between 65 and 72 years of age'

Diabetes (by 65 years)

Exposed to dangerous conditions at work (by 54 years)

$20 / 236$

$28 / 658$

$10 / 740$

$5.62(4.08 \text { to } 7.75)^{\star \star \star}$ $6.93(4.18 \text { to } 11.49)^{\star \star \star}$

$4.24(3.04 \text { to } 5.91)^{\star \star \star}$

$<0.0001^{\mathrm{C}}$

$<0.0001^{\mathrm{C}}$

$<0.0001^{\mathrm{C}}$

$2.03(1.38 \text { to } 3.00)^{\star \star \star} \quad 0.0007^{\mathrm{C}}$

$1.59(1.16 \text { to } 2.18)^{* *} \quad 0.0070^{\mathrm{C}}$

$4.00(1.94 \text { to } 8.27)^{\star \star *} \quad 0.0002^{\mathrm{F}}$

$2.02(1.31 \text { to } 3.12)^{\star \star} \quad 0.0002^{\mathrm{F}}$

$0.53(0.32 \text { to } 0.89)^{\star} \quad 0.0330^{\mathrm{C}}$

Menstruated in last 12 months (by 54 years)

Yes
Yes

$3.37(2.23 \text { to } 5.09)^{\star \star \star}$

$3.21(2.34 \text { to } 4.39)^{\star \star \star}$

$0.34(0.21 \text { to } 0.57)^{\star \star \star}$

$<0.0001^{\mathrm{C}}$

$<0.0001^{\mathrm{C}}$

$0.0002^{\mathrm{C}}$

Present

Present

The 'age at survey year' of 54, 65 and 72 represent survey years 1993, 2004 and 2011, respectively. Analyses associated with the 'MI by 72 years of age' data set included independent variables from all WLS survey years, 1957-2011, while analyses associated with the 'Ml between 65 and 72 years of age' data set included only independent variables from WLS survey year 2004 or earlier.

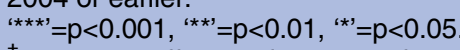

${ }^{\dagger}$ Multiple coefficients found significant for this variable using logistic regression.

C, $\chi^{2}$ test; F, Fisher's Exact test. 
'MI Between 65-72 Years of Age'

MI Associated Factors for Females

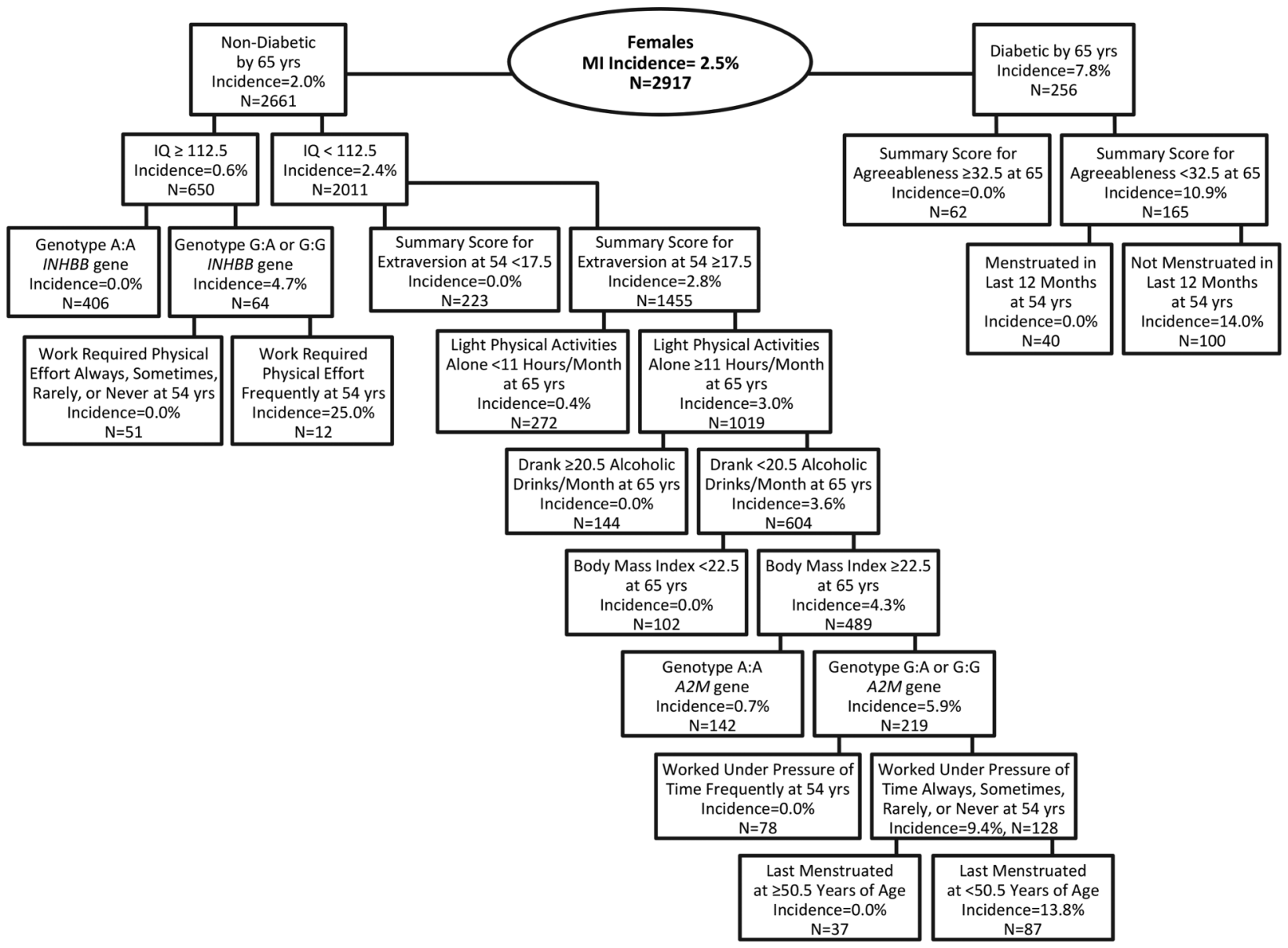

Figure 4 RP tree showing interactions among Ml-associated factors for women who had a Ml between 65 and 72 years of age in the WLS cohort, with MI incidence listed at each node in the tree. MI, myocardial infarction; RP, recursive partitioning; WLS, Wisconsin Longitudinal Study.

work conditions at 54, which was significantly associated with MI by LR and $\chi^{2}$ and deemed an 'important' factor by RF, and having menstruated in the last 12 months at 54 , which was significantly associated by LR and $\chi^{2}$ and present in the RP tree (table 3B).

\section{SNP associations with MI}

None of the genetic variables tested appeared among the RF 'important' factors in any of the groups analysed. Although this study found several SNPs that were associated with MI by RP, specifically the CYP11B2 (rs1799998), the FADS2 (rs174575) and the IL6 (rs1800795) gene SNPs in men up to 72, and the INHBB (rs11902591) and $A 2 M$ (rs669) gene SNPs in women between 65 and 72 years, none of these were significantly associated with MI according to LR or $\chi^{2}$ after adjustment for multiple testing.

\section{Logical bounding}

Logical bounding of missing data and subsequent LR analysis (see the 'Methods' section) showed that all but one of the factors associated with MI identified by this study were robust to missing data, as they all remained statistically significant on both sides of the logical bounding procedure (results not shown). The only factor that did not remain significant was exposure to dangerous work conditions for women who had a MI between 65 and 72 years of age, when all missing data points were coded as 'yes', suggesting that this result was less robust or more sensitive to missing data, which should be considered when evaluating the results.

\section{DISCUSSION}

This study identified factors associated with MI among participants in the WLS. For men, the factor most associated with reported MI by 72 years old was having had a stroke by 65 . High cholesterol, diabetes, high blood pressure and family history were also identified as top factors for men up to 72 years, as well as exposure to dangerous working conditions, which has not previously been identified as associated with MI in men. Stroke and diabetes by 65 were most associated with MI in men over 
65 years in the WLS cohort. We identified being diabetic by 65 as the factor most associated with reported MI in women up to 72 years old. High cholesterol, being unmarried, dissatisfaction with finances, not engaging in physical activity and high blood pressure were also identified as associated with MI in women up to 72 years. Among women who had their MI after age 65 , being diabetic remained the most associated factor. However, exposure to dangerous working conditions, also newly associated with MI in women, and whether they were still menstruating at 54 were also determined to be associated with MI for women in this group. For most of the factors listed, exposure time had a large effect on MI occurrence, for men and women in the WLS cohort. Interactions among these and other factors greatly affected MI occurrence in men and women. Furthermore, results showed that for men and women, not only do the MI-associated factors become less associated as people age, but many of the factors change or are different between younger and older people.

\section{Men}

MI by 72 years of age

Results showed that $18.1 \%$ of men reported a MI to the WLS by age 72 . Stroke by 65 was associated with the greatest increase in LR odds of MI among these men (table 2A). The other factors associated with MI in this group include having high cholesterol, diabetes, high blood pressure, exposure to dangerous working conditions and having a parent or sibling who had a MI before age 55. Stroke has been cited as a risk factor for MI, ${ }^{98} 99$ and MI has been established as a risk factor for stroke in prior studies, ${ }^{100-102}$ and according to the American Stroke Association ${ }^{103}$ stroke risk is doubled among those who have experienced MI due to atherosclerosis. Furthermore, high cholesterol, diabetes and high blood pressure represent three of the four conventional 'key' risk factors for MI, and their association with heart disease and MI risk is well characterised in the literature. ${ }^{4-6} 910104$ A family history of heart disease has been shown to be a significant contributor to MI risk in previous studies. ${ }^{61} 62105106$ However, our study is the first to identify a link between exposure to dangerous working conditions and MI. Consistent with this, a number of studies show that stress in the workplace is associated with an increased risk of MI. ${ }^{49}{ }^{107-109}$ The increased odds of MI noted with a diagnosis by 65 years old rather than 72 (among above factors) suggest that exposure time is an important determinant in whether one experiences a MI or not. Although in this particular cohort having high cholesterol increased one's odds of MI by 3.3-fold, regardless of whether it was diagnosed by 65 or 72, prior studies have shown that those who are diagnosed with high cholesterol at a younger age ( $<50$ years) are more likely to experience heart disease in their lifetime. ${ }^{110-112}$
This study demonstrates that interactions among factors associated with MI lead to large changes in MI prevalence (figure 1). While combinations of high cholesterol, diabetes, smoking and lower alcohol consumption were associated with increased prevalence and interacted with lesser-known factors such as depression, genetic factors, and dangerous working conditions to increase prevalence up to $50 \%$, other factors including increased alcohol consumption, higher household income and higher education tended to lower prevalence, in some cases down to $0.0 \%$ even when other top MI risk factors were present. For example, high cholesterol, smoking and being diabetic are associated with higher MI prevalence, but for the subset of men who completed more than 5.5 years of college, prevalence in the WLS dropped to $0.0 \%$ compared to those completing $<5.5$ years of college, whose MI prevalence was a whopping $53.3 \%$. This suggests that factors should not be evaluated individually, but rather the interaction among factors has to be considered when determining associations with MI (additional discussion of RP results can be found in online supplementary information 3).

\section{MI between 65 and 72 years of age}

Only $5.9 \%$ of men reported a MI between 65 and 72 years to the WLS, versus $18.1 \%$ who ever reported MI by 72 years, therefore the majority of MIs reported by men to the WLS and included in this study occurred before age 65 . The factors most associated with MI for men between the ages of 65 and 72 years were having had a stroke and being diabetic, both by 65 years old (table 2B). These two factors were identified by both analyses of $\mathrm{MI}$ in men, suggesting that these factors are strongly associated with MI in men at any age. Interestingly, the odds of MI in the first analysis for men who ever had a MI by 72 were increased compared to the odds of MI between 65 and 72 years old, both for having had a stroke by 65 (5.0-fold vs 4.1 -fold increase, respectively) and for being diabetic by 65 (3.2-fold vs 2.7-fold increase, respectively), suggesting that the key risk factors for MI become less predictive as men age, as supported by previous studies. ${ }^{5}{ }^{55}$ Additionally, the loss of two factors associated with MI in men from the first analysis, having high cholesterol or having high blood pressure (table 2B), suggests that factors associated with MI are different in younger versus older men. This result is supported by the fact that RP analysis identified fewer days/month drinking alcoholic beverages at 65 as the only factor affecting MI among men 65-72 years old, with a 2.7-fold increase in odds of MI among those who drank alcohol $<8.5$ days/month $(7.7 \%$ vs $2.9 \%$; figure 2 ). This supports prior studies proposing an insulating effect of regular moderate alcohol consumption, specifically in older adults ( $\geq 65$ years), ${ }^{113-115}$ but still suggests that the 'known' risk factors for MI change with age, at least for men in the WLS cohort. 


\section{Women}

$\mathrm{MI}$ by 72 years of age

This study found that $7.5 \%$ of women reported MI to the WLS by age 72 , which was $10.6 \%$ less than that reported in men for this age group. LR ORs indicated that being diabetic by 54 was associated with the greatest increase in odds of MI (table 3A). The other factors associated with MI for women in this group include being diabetic (any age), having high cholesterol, being unmarried, dissatisfaction with financial situation, not engaging in physical activity and having high blood pressure. Being diabetic (by 65) was also the single most important factor for MI among women up to 72 according to RP results (figure 3), with a 4.6-fold increase in MI prevalence among diabetic women (22.4\% vs $4.9 \%$ ). Diabetes has been shown in prior studies to be a strong predictor of MI risk in women. ${ }^{116}$ As seen in men in this study, high cholesterol and high blood pressure are strongly associated with MI risk in women, as supported by previous studies. Marriage is a well-accepted indicator of MI risk and an even better indicator of one's recovery and health after experiencing an MI. ${ }^{117-122}$ Dissatisfaction with one's financial situation was linked with MI risk in women in one prior study, ${ }^{123}$ and another study showed an association between 'perceived financial status' and MI risk among employed women. ${ }^{124}$ Dissatisfaction with one's financial situation could also be associated with financial stress, which has been linked to increased MI risk in multiple studies. ${ }^{45}{ }^{125}$ Reduced prevalence of MI in women in the WLS cohort who engaged in physical activity when they were about 67 years old is supported by numerous studies on the effects of physical inactivity and MI risk. ${ }^{35} 4055$ An even larger reduction in MI prevalence was noted among those who often engaged in light physical activity with others when 67 (0.34) versus those who often engaged in vigorous physical activity alone when 67 (0.53), suggesting that type of physical activity is less important and spending time with others may play a larger role for women when it comes to reducing MI risk. This is supported by previous studies showing that for women having 'social support' decreases risk of MI. ${ }^{126} 127$ Furthermore, our study suggests that physical inactivity may play a more important role for women than for men when it comes to MI (table 3A), specifically concerning $\mathrm{MI}$ in those $<65$ years old, as supported by previous studies. 55

In addition to identifying being diabetic by 65 as the most associated factor for women up to 72 years in the WLS cohort (figure 3), RP analysis showed that among those women who were non-diabetic at 65 , the interaction of having high blood pressure by 65 and smoking $\geq 24.5$ years by 54 more than tripled MI prevalence, again demonstrating the importance of considering interactions among factors when predicting MI risk (additional discussion of RP results can be found in online supplementary information 4). As in men, our study suggests that exposure time to certain factors is an important determinant in whether a woman has a MI or not. For example, odds of MI increase for diabetic women, but the younger a woman is when she is diagnosed, the higher her odds for eventually experiencing a MI, with a 6.9-fold, 5.6-fold and 4.2-fold increase in odds among those diagnosed by 54, 65 and 72 years old, respectively $\left(\mathrm{R}^{2}=0.98\right)$. However, this association does not hold for all medical health conditions in women in the WLS. For example, high blood pressure by 54 was not associated with MI, but was associated with increased odds of MI at 65 years (3.2-fold), and this increase in odds remained stable at 72 years (3.4-fold). Further study will need to be conducted in order to determine the exact mechanisms by which exposure time affects one's odds of having a MI and which MI-associated factors are more susceptible to this effect.

\section{MI between 65 and 72 years of age}

Only $2.5 \%$ of women reported a MI between 65 and 72 years to the WLS-much lower than that noted among women who ever reported a MI by 72 years old $(7.5 \%)$. The factor associated with the highest odds of MI for women in this age group was being diabetic by 65 years old (table $3 \mathrm{~B}$ ), similar to women who ever had a MI by 72 years. RP analysis confirmed diabetes as the top factor associated with MI among women 65 to 72 years old (figure 4), again suggesting that this is potentially the most important factor associated with MI in women. However, just as in men, this factor is more associated with MI among younger women, or including those $<65$ years old, with a 5.62 -fold increase as compared to the 4.25-fold increase in odds among those who experienced a MI after 65 years old (table 3B). Even so, this remained the most important factor associated with MI among women in the WLS at any age. This result is in agreement with what is known about diabetes and MI risk for women, as it has been shown that being diabetic increases not only a woman's MI risk, but also her risk for fatal coronary heart disease, ischaemic stroke, cardiovascular mortality and all-cause mortality. $^{116} 128-130$

Additionally and interestingly, exposure to dangerous conditions at work (at 54 years old) was determined to be associated with MI for women 65-72 years old (2.2-fold increase; table 3B), just as exposure to dangerous work conditions (at 65 years) was a top factor for men who ever had a MI by 72 years (1.4-fold increase; table 2A). This may represent a possible new risk factor for MI, although more research is needed to confirm this result. Still it suggests that not only do MI-associated factors become less associated as women age, but those factors may change between younger and older women. This is supported by the last MI-associated factor for women 65-72 years old, whether she still had her menstrual period at 54 (0.46-fold decrease in odds; table 3B). The age at which a woman experiences her last menstrual cycle affects the age at which large, lasting hormonal changes take place in her body and has a very large 
impact on her ageing and overall health. Supporting the results of this study, it has been shown that the earlier a woman stops menstruating, the shorter her lifespan and the more health problems she will encounter in later years, including an increased risk of MI. ${ }^{131-141}$ Indeed, we have previously demonstrated in the WLS that the earlier a woman stops menstruating, the shorter her lifespan will be (Yonker et al., 2013). Our results are further supported by studies showing that hormone replacement therapy can ameliorate the effects of natural or surgical menopause, specifically in younger women. ${ }^{142}{ }^{144}$ In other words, the longer a woman's hypothalamic-pituitary-gonadal axis remains in balance, the lower her odds of experiencing a MI later in life (between 65 and 72 years old). The 'exposure to dangerous conditions at work' factor was shown to be more sensitive to missing data points in our logical bounding procedure, therefore additional work is needed to follow-up on this finding. However, this same factor was identified in men and women in this study, lending support to our result.

Among those women 65-72 years old in the 'riskiest' group, those who were diabetic by 65 , the interaction of being less agreeable and having stopped menstruating by 54 resulted in a doubling of MI incidence, while those who were more agreeable or who did still menstruate when they were 54 experienced no MI, despite having the top MI-associated factor for women (figure 4). Among women who were non-diabetic at 65 , the interaction of three other identified factors was associated with an increased MI incidence to 25\% - 3.2 times higher incidence than that noted before the interaction (see the 'Results' section). These examples highlight the importance of interactions among factors when predicting one's MI risk (figure 4; additional discussion of RP results can be found in online supplementary information 5).

\section{SNP associations with MI}

Although this study found several SNPs that were associated with MI by RP, none of these were significantly associated with MI according to LR or $\chi^{2}$ after adjustment for multiple testing. Interestingly, while some studies have found an association of CYP11B2 (rs1799998) and IL6 (rs1800795) with cardiovascular disease or MI, ${ }^{145-152}$ other studies have not found an association. ${ }^{153-156}$ Future genome-wide association studies will provide more definite data as to the role these SNPs play in the disease.

\section{Limitations}

Few studies have included the breadth of factors evaluated in the present study; however, despite high participant response rates to the WLS, our largest limitation was the loss of WLS participants due to the design of the two dependent variables, attrition from the WLS and missing data common to survey studies (see online supplementary table S1). If the population of participants excluded from the study was somehow different from the population included, it may have created a bias which could affect our results. However, as stated above, missing data is a limitation in every observational study and is an unavoidable consequence of using longitudinal survey data. Furthermore, the logical bounding procedure we performed showed that all but one of the 'overall' MI-associated factors identified were robust to missing data, lending support to our results.

An additional limitation in this study is that it is likely that some reported MIs may have occurred before some of the independent variables were measured, specifically for the 'MI by 72 years of age' analyses. Our data set did not include the dates of occurrence of all independent variables, therefore it was impossible to run a 'time-to-event' or survival analysis on these data. However, we were interested in factors present in participants who ever experienced a MI in their lifetime (up to 72 years), regardless of when their MI occurred. Therefore, this part of our analysis is a case-control retrospective study. Owing to the mentioned complications with the first analysis, we completed a second analysis in which all of the independent variables occurred before the participant's reported MI. Although this design reduced the number of participants included in the second analysis, it allowed us to determine which factors are associated with MI before the MI occurs and therefore are potentially predictive of MI. This part of our analysis is a true cohort study.

Additional limitations of the current study include limitations associated with ICD codes in death records and limitations in death records recovered by the WLS. Furthermore, Rosamond et $a l^{157}$ found that when MI are self-reported, the numbers are often an overestimation. Again, these limitations are an unavoidable consequence of using longitudinal survey data, but still must be considered when interpreting results. Additionally, the predictive value of our genetic data was limited because of user bias in selection of SNPs; other genetic variants that we did not examine in this study may have provided information about crucial interactions involved with MI. Furthermore, the WLS has social-factor homogeneities, such as participants being almost exclusively non-Hispanic white people with middle-class to upper-middle-class backgrounds. Future directions for research will involve using these same machine-learning methodologies on more complete genetic profiles, such as from genome-wide SNP or sequencing data, with which we will be able to explore all genetic interaction possibilities rather than a limited subset of variants.

\section{CONCLUSIONS}

It has previously been shown that at least one of four key risk factors-smoking, high blood pressure, high cholesterol or diabetes (mellitus) -was observed in more than $80-90 \%$ of patients experiencing MI, and all of these risks combined account for a population attributable risk $>90 \%$ for all MI-for men and women, old and young, worldwide. ${ }^{55}$ However, our study indicated that: (1) the main factors associated with MI are different between men (high cholesterol, diabetes, stroke, high 
blood pressure and family history) and women (diabetes, high cholesterol, being unmarried, dissatisfaction with financial situation, physical inactivity, high blood pressure and loss of menstruation); (2) interactions among MI-associated factors have a large influence on MI occurrence; (3) factors associated with MI change and associations weaken after 65 years of age in both sexes and (4) the interaction of factors can be associated with large reductions in MI prevalence, to near zero, even in the presence of one or more of the 4 key risk factors for MI. In addition to identifying the above recognised factors associated with MI, we found one previously unidentified factor associated with MI (exposure to dangerous conditions at work) among WLS participants, which may represent a 'new' risk factor for MI. Larger genetic studies are required to elaborate on the modest genetic interactions identified in this study.

\section{Author affiliations}

${ }^{1}$ Department of Sociology, University of Wisconsin, Madison, Wisconsin, USA

${ }^{2}$ La Follete School of Public Affairs, University of Wisconsin, Madison,

Wisconsin, USA

${ }^{3}$ Department of Medicine, University of Wisconsin-Madison School of Medicine and Public Health, Madison, Wisconsin, USA

${ }^{4}$ Geriatric Research, Education and Clinical Center, Veterans Administration Hospital, Madison, Wisconsin, USA

${ }^{5}$ School of Exercise, Biomedical and Health Sciences, Edith Cowan University, Joondalup, Western Australia, Australia

Acknowledgements This research used data from the Wisconsin Longitudinal Study (WLS) of the University of Wisconsin-Madison. This material is the result of work supported with resources at the William S. Middleton Memorial Veterans Hospital, Madison, WI. This article is Geriatrics Research, Education and Clinical Center VA paper 2016-002.

Disclaimer The opinions expressed herein are those of the authors. The contents do not represent the views of the Department of Veterans Affairs or the US government.

Contributors CSA and TG conceptualised the study. CLR, PH and CSA collected saliva samples and performed genotyping analyses. TG, JAY, VC and CLR identified the variables and performed the statistical analyses on the Wisconsin Longitudinal Study data set. CSA, JAY and PH directed the statistical analyses. TG and CSA drafted the manuscript. All authors critically reviewed the manuscript and approved the final version.

Funding Since 1991, the WLS has been supported principally by the National Institute on Aging (AG-9775, AG-21079 and AG-033285), with additional support from the Vilas Estate Trust, the National Science Foundation, the Spencer Foundation and the Graduate School of the University of WisconsinMadison.

\section{Competing interests None declared.}

Ethics approval Ethics approval was provided by the Health Sciences Institutional Review Board, University of Wisconsin-Madison.

Provenance and peer review Not commissioned; externally peer reviewed.

Data sharing statement A public use file of data from the Wisconsin Longitudinal Study collected over the last 58 years is available from the WLS University of Wisconsin-Madison, 1180 Observatory Drive, Madison, WI 53706, and online at http://www.ssc.wisc.edu/wlsresearch/data

Open Access This is an Open Access article distributed in accordance with the Creative Commons Attribution Non Commercial (CC BY-NC 4.0) license, which permits others to distribute, remix, adapt, build upon this work noncommercially, and license their derivative works on different terms, provided the original work is properly cited and the use is non-commercial. See: http:// creativecommons.org/licenses/by-nc/4.0/

\section{REFERENCES}

1. Prevention CfDCa. Heart Disease Facts: Centers for Disease Control and Prevention. 2014 (updated 29 Oct 2014). http://www. cdc.gov/heartdisease/facts.htm (accessed 11 Dec 2014).

2. Murphy SL, Xu J, Kochanek KD. Deaths: final data for 2010. Natl Vital Stat Rep 2013;61:1-117.

3. Mozaffarian D, Benjamin EJ, Go AS, et al. Heart disease and stroke statistics-2015 update: a report from the American Heart Association. Circulation 2015;131:e29-322.

4. González-Pacheco H, Vargas-Barrón J, Vallejo M, et al. Prevalence of conventional risk factors and lipid profiles in patients with acute coronary syndrome and significant coronary disease. Ther Clin Risk Manag 2014;10:815-23.

5. Yusuf S, Hawken S, Ounpuu S, et al. Effect of potentially modifiable risk factors associated with myocardial infarction in 52 countries (the INTERHEART study): case-control study. Lancet 2004;364:937-52.

6. Khot UN, Khot MB, Bajzer CT, et al. Prevalence of conventional risk factors in patients with coronary heart disease. JAMA 2003;290:898-904.

7. James PA, Oparil S, Carter BL, et al. 2014 evidence-based guideline for the management of high blood pressure in adults: report from the panel members appointed to the Eighth Joint National Committee (JNC 8). JAMA 2014;311:507-20.

8. Psaty BM, Furberg CD, Kuller LH, et al. Association between blood pressure level and the risk of myocardial infarction, stroke, and total mortality: the cardiovascular health study. Arch Intern Med 2001;161:1183-92.

9. Stone NJ, Robinson JG, Lichtenstein AH, et al. 2013 ACC/AHA guideline on the treatment of blood cholesterol to reduce atherosclerotic cardiovascular risk in adults: a report of the American College of Cardiology/American Heart Association Task Force on Practice Guidelines. Circulation 2014;129(Suppl 2): S1-S45.

10. Langsted A, Freiberg JJ, Tybjaerg-Hansen A, et al. Nonfasting cholesterol and triglycerides and association with risk of myocardial infarction and total mortality: the Copenhagen City Heart Study with 31 years of follow-up. J Intern Med 2011;270:65-75.

11. Wilson PW, D'Agostino RB, Levy D, et al. Prediction of coronary heart disease using risk factor categories. Circulation 1998:97:1837-47.

12. Austin MA, Breslow JL, Hennekens $\mathrm{CH}$, et al. Low-density lipoprotein subclass patterns and risk of myocardial infarction. JAMA 1988;260:1917-21.

13. Stamler J, Wentworth D, Neaton JD. Is relationship between serum cholesterol and risk of premature death from coronary heart disease continuous and graded? Findings in 356,222 primary screenees of the Multiple Risk Factor Intervention Trial (MRFIT). JAMA 1986;256:2823-8.

14. Huxley R, Barzi F, Woodward M. Excess risk of fatal coronary heart disease associated with diabetes in men and women: meta-analysis of 37 prospective cohort studies. BMJ 2006;332:73-8.

15. Hanefeld M, Fischer S, Julius U, et al. Risk factors for myocardial infarction and death in newly detected NIDDM: the Diabetes Intervention Study, 11-year follow-up. Diabetologia 1996;39: 1577-83.

16. Koskinen $\mathrm{P}$, Manttari M, Manninen V, et al. Coronary heart disease incidence in NIDDM patients in the Helsinki Heart Study. Diabetes Care 1992;15:820-5

17. Öberg M, Jaakkola MS, Woodward A, et al. Worldwide burden of disease from exposure to second-hand smoke: a retrospective analysis of data from 192 countries. Lancet 2011;377:139-46.

18. Critchley JA, Capewell S. Mortality risk reduction associated with smoking cessation in patients with coronary heart disease: a systematic review. JAMA 2003;290:86-97.

19. Prescott $\mathrm{E}$, Hippe $M$, Schnohr $\mathrm{P}$, et al. Smoking and risk of myocardial infarction in women and men: longitudinal population study. BMJ 1998;316:1043-7.

20. Parish S, Collins R, Peto R, et al. Cigarette smoking, tar yields, and non-fatal myocardial infarction: 14,000 cases and 32,000 controls in the United Kingdom. The International Studies of Infarct Survival (ISIS) Collaborators. BMJ 1995;311:471-7.

21. Neaton JD, Wentworth D. Serum cholesterol, blood pressure, cigarette smoking, and death from coronary heart disease. Overall findings and differences by age for 316,099 white men. Multiple 
Risk Factor Intervention Trial Research Group. Arch Intern Med 1992;152:56-64.

22. Thomsen M, Nordestgaard BG. Myocardial infarction and ischemic heart disease in overweight and obesity with and without metabolic syndrome. JAMA Intern Med 2014;174:15-22.

23. Després J-P. Body fat distribution and risk of cardiovascular disease: an update. Circulation 2012;126:1301-13.

24. Logue J, Murray HM, Welsh P, et al. Obesity is associated with fatal coronary heart disease independently of traditional risk factors and deprivation. Heart 2011;97:564-8.

25. Yusuf S, Hawken S, Ounpuu S, et al. Obesity and the risk of myocardial infarction in 27,000 participants from 52 countries: a case-control study. Lancet 2005;366:1640-9.

26. Willett WC, Manson JE, Stampfer MJ, et al. Weight, weight change, and coronary heart disease in women. Risk within the 'normal' weight range. JAMA 1995;273:461-5.

27. Hubert HB, Feinleib M, McNamara PM, et al. Obesity as an independent risk factor for cardiovascular disease: a 26-year follow-up of participants in the Framingham Heart Study. Circulation 1983;67:968-77.

28. Hoekstra T, Beulens JWJ, van der Schouw YT. Cardiovascular disease prevention in women: impact of dietary interventions. Maturitas 2009:63:20-7.

29. Iqbal R, Anand S, Ounpuu S, et al. Dietary patterns and the risk of acute myocardial infarction in 52 countries: results of the INTERHEART study. Circulation 2008:118:1929-37.

30. Hu FB. Diet and cardiovascular disease prevention the need for a paradigm shift. J Am Coll Cardiol 2007;50:22-4.

31. Rivellese AA. Diet and cardiovascular disease: Beyond cholesterol. Nutr Metab Cardiovasc Dis 2005;15:395-8.

32. Martínez-González MA, Fernandez-Jarne E, Serrano-Martinez M, et al. Mediterranean diet and reduction in the risk of a first acute myocardial infarction: an operational healthy dietary score. Eur J Nutr 2002:41:153-60.

33. Joshipura KJ, Hu FB, Manson JE, et al. The effect of fruit and vegetable intake on risk for coronary heart disease. Ann Intern Med 2001;134:1106-14.

34. Liu S, Stampfer MJ, Hu FB, et al. Whole-grain consumption and risk of coronary heart disease: results from the Nurses' Health Study. Am J Clin Nutr 1999;70:412-19.

35. Daviglus ML, Stamler J, Orencia AJ, et al. Fish consumption and the 30-year risk of fatal myocardial infarction. $N$ Engl J Med 1997;336:1046-53.

36. Ascherio A, Hennekens $\mathrm{CH}$, Buring JE, et al. Trans-fatty acids intake and risk of myocardial infarction. Circulation 1994;89:94-101.

37. Lee IM, Shiroma EJ, Lobelo F, et al. Effect of physical inactivity on major non-communicable diseases worldwide: an analysis of burden of disease and life expectancy. Lancet 2012;380:219-29.

38. Li J, Siegrist J. Physical activity and risk of cardiovascular disease - a meta-analysis of prospective cohort studies. Int $J$ Environ Res Public Health 2012;9:391-407.

39. Chomistek AK, Chiuve SE, Jensen MK, et al. Vigorous physical activity, mediating biomarkers, and risk of myocardial infarction. Med Sci Sports Exerc 2011;43:1884-90.

40. Sattelmair J, Pertman J, Ding EL, et al. Dose-response between physical activity and risk of coronary heart disease: a meta-analysis. Circulation 2011;124:789-95.

41. Lakka TA, Venalainen JM, Rauramaa R, et al. Relation of leisure-time physical activity and cardiorespiratory fitness to the risk of acute myocardial infarction. $N$ Engl J Med 1994;330:1549-54.

42. Leong DP, Smyth A, Teo KK, et al. Patterns of alcohol consumption and myocardial infarction risk: observations from 52 countries in the INTERHEART case-control Study. Circulation 2014;130:390-8

43. Roerecke M, Rehm J. Alcohol consumption, drinking patterns, and ischemic heart disease: a narrative review of meta-analyses and a systematic review and meta-analysis of the impact of heavy drinking occasions on risk for moderate drinkers. $B M C M e d$ 2014;12:182

44. Brien SE, Ronksley PE, Turner BJ, et al. Effect of alcohol consumption on biological markers associated with risk of coronary heart disease: systematic review and meta-analysis of interventional studies. BMJ 2011;342:d636. http://dx.doi.org/

45. Ronksley PE, Brien SE, Turner BJ, et al. Association of alcohol consumption with selected cardiovascular disease outcomes: a systematic review and meta-analysis. BMJ 2011;342:d671.

46. Camargo CA Jr, Stampfer MJ, Glynn RJ, et al. Moderate alcohol consumption and risk for angina pectoris or myocardial infarction in US male physicians. Ann Intern Med 1997;126:372-5.
47. Gaziano JM, Buring JE, Breslow JL, et al. Moderate alcohol intake, increased levels of high-density lipoprotein and its subfractions, and decreased risk of myocardial infarction. $N$ Engl $J$ Med 1993;329:1829-34.

48. Mostofsky E, Maclure M, Sherwood JB, et al. Risk of acute myocardial infarction after death of a significant person in one's life: the determinants of Ml onset study. Circulation 2012;125:491-6.

49. Rosengren A, Hawken S, Ôunpuu S, et al. Association of psychosocial risk factors with risk of acute myocardial infarction in 11119 cases and 13648 controls from 52 countries (the INTERHEART study): case-control study. Lancet 2004;364:953-62.

50. Peter R, Siegrist J, Hallqvist J, et al. Psychosocial work environment and myocardial infarction: improving risk estimation by combining two complementary job stress models in the SHEEP Study. J Epidemiol Community Health 2002;56:294-300.

51. Mittleman MA, Maclure M, Sherwood JB, et al. Triggering of acute myocardial infarction onset by episodes of anger. Circulation 1995;92:1720-5.

52. van Loo HM, van den Heuvel ER, Schoevers RA, et al. Sex dependent risk factors for mortality after myocardial infarction: individual patient data meta-analysis. BMC Med 2014; $12: 242$

53. Evangelista O, McLaughlin MA. Review of cardiovascular risk factors in women. Gend Med 2009;6(Suppl 1)::17-36. .

54. Schenck-Gustafsson K. Risk factors for cardiovascular disease in women. Maturitas 2009;63:186-90.

55. Anand SS, Islam S, Rosengren A, et al. Risk factors for myocardial infarction in women and men: insights from the INTERHEART study. Eur Heart J 2008;29:932-40.

56. Ordovas JM. Gender, a significant factor in the cross talk between genes, environment, and health. Gend Med 2007;4(Suppl B): S111-22.

57. Regitz-Zagrosek V, Lehmkuhl E, Mahmoodzadeh S. Gender aspects of the role of the metabolic syndrome as a risk factor for cardiovascular disease. Gend Med 2007;4(Suppl B): S162-77.

58. Jousilahti P, Vartiainen E, Tuomilehto J, et al. Sex, age, cardiovascular risk factors, and coronary heart disease: a prospective follow-up study of 14786 middle-aged men and women in Finland. Circulation 1999;99:1165-72.

59. Castelli WP, Wilson PWF, Levy D, et al. Cardiovascular risk factors in the elderly. Am J Cardiol 1989;63:12H-19H.

60. Canto JG, Kiefe Cl, Rogers WJ, et al. Number of coronary heart disease risk factors and mortality in patients with first myocardial infarction. JAMA 2011;306:2120-7.

61. Chow CK, Islam S, Bautista L, et al. Parental history and myocardial infarction risk across the world: the INTERHEART Study. J Am Coll Cardiol 2011:57:619-27.

62. Friedlander Y, Siscovick DS, Weinmann S, et al. Family history as a risk factor for primary cardiac arrest. Circulation 1998;97: 155-60.

63. Myers RH, Kiely DK, Cupples LA, et al. Parental history is an independent risk factor for coronary artery disease: the Framingham Study. Am Heart J 1990;120:963-9.

64. Hunt KJ, Williams K, Resendez RG, et al. All-cause and cardiovascular mortality among diabetic participants in the San Antonio Heart Study: evidence against the "Hispanic Paradox". Diabetes Care 2002;25:1557-63.

65. Yang Y, Ruiz-Narvaez E, Kraft P, et al. Effect of apolipoprotein E genotype and saturated fat intake on plasma lipids and myocardial infarction in the Central Valley of Costa Rica. Hum Biol 2007;79:637-47.

66. Lambert JC, Brousseau T, Defosse V, et al. Independent association of an APOE gene promoter polymorphism with increased risk of myocardial infarction and decreased APOE plasma concentrations-the ECTIM study. Hum Mol Genet 2000;9:57-61.

67. Freeman DJ, Samani NJ, Wilson V, et al. A polymorphism of the cholesteryl ester transfer protein gene predicts cardiovascular events in non-smokers in the West of Scotland Coronary Prevention Study. Eur Heart J 2003;24:1833-42.

68. Kuivenhoven JA, Jukema JW, Zwinderman AH, et al. The role of a common variant of the cholesteryl ester transfer protein gene in the progression of coronary atherosclerosis. N Engl J Med 1998;338:86-93.

69. Fumeron F, Betoulle D, Luc G, et al. Alcohol intake modulates the effect of a polymorphism of the cholesteryl ester transfer protein gene on plasma high density lipoprotein and the risk of myocardial infarction. J Clin Invest 1995;96:1664-71. 
70. Qi L, Ma J, Qi Q, et al. Genetic risk score and risk of myocardial infarction in Hispanics. Circulation 2011;123:374-80.

71. Levy D, Wilson PWF, Anderson KM, et al. Stratifying the patient at risk from coronary disease: New insights from the Framingham Heart Study. Am Heart J 1990;119(Part 2):712-17.

72. Canto JG, Rogers WJ, Goldberg RJ, et al. Association of age and sex with myocardial infarction symptom presentation and in-hospital mortality. JAMA 2012;307:813-22.

73. Hanratty B, Lawlor D, Robinson MB, et al. Sex differences in risk factors, treatment and mortality after acute myocardial infarction: an observational study. J Epidemiol Community Health 2000;54:912-16.

74. Sewell WH. As we age: the Wisconsin Longitudinal Study, 19572001. Madison (WI): Center for Demography and Ecology, University of Wisconsin-Madison, 2001.

75. Herd P, Carr D, Roan C. Cohort profile: Wisconsin Longitudinal Study (WLS). Int J Epidemiol 2014;43:34-41.

76. Roetker NS, Yonker JA, Lee C, et al. Multigene interactions and the prediction of depression in the Wisconsin Longitudinal Study. BMJ Open 2012;2:pii: e000944

77. Belbin O, Dunn JL, Ling Y, et al. Regulatory region single nucleotide polymorphisms of the apolipoprotein $\mathrm{E}$ gene and the rate of cognitive decline in Alzheimer's disease. Hum Mol Genet 2007;16:2199-208.

78. Lahoz C, Schaefer EJ, Cupples LA, et al. Apolipoprotein E genotype and cardiovascular disease in the Framingham Heart Study. Atherosclerosis 2001;154:529-37.

79. Corder EH, Saunders AM, Risch NJ, et al. Protective effect of apolipoprotein E type 2 allele for late onset Alzheimer disease. Nat Genet 1994;7:180-4.

80. Weisgraber KH, Rall SC, Mahley RW. Human E apoprotein heterogeneity. Cysteine-arginine interchanges in the amino acid sequence of the apo-E isoforms. J Biol Chem 1981;256:9077-83.

81. Weisgraber KH, Innerarity TL, Mahley RW. Abnormal lipoprotein receptor-binding activity of the human $\mathrm{E}$ apoprotein due to cysteine-arginine interchange at a single site. $J$ Biol Chem 1982;257:2518-21.

82. Breiman L, Friedman JH, Olshen RA, et al. Classification and regression trees. Boca Raton, FL: Chapman and Hall/CRC 1984:368.

83. Altman DG. Practical statistics for medical research. London, New York: Chapman and Hall, 1991.

84. Haldane JB. The estimation and significance of the logarithm of a ratio of frequencies. Ann Hum Genet 1956;20:309-11.

85. Gart JJ, Zweifel JR. On the bias of various estimators of the logit and its variance with application to quantal bioassay. Biometrika 1967;54:181-7 . http://dx.doi.org/10.2307/2333861

86. Strobl C, Malley J, Tutz G. An introduction to recursive partitioning: rationale, application, and characteristics of classification and regression trees, bagging, and random forests. Psychol Methods 2009;14:323-48.

87. Breiman L. Random forests. Mach Learn 2001;45:5-32.

88. Breiman L. Bagging predictors. Mach Learn 1996;24:123-40.

89. Amit $Y$, Geman D. Shape quantization and recognition with randomized trees. Neural Comput 1997;9:1545-88.

90. Roshan U, Chikkagoudar S, Wei Z, et al. Ranking causal variants and associated regions in genome-wide association studies by the support vector machine and random forest. Nucleic Acids Res 2011;39:e62.

91. Jiang R, Tang $\mathrm{W}, \mathrm{Wu} \mathrm{X}$, et al. A random forest approach to the detection of epistatic interactions in case-control studies. BMC Bioinformatics 2009;10(Suppl 1):S65.

92. Shi T, Seligson D, Belldegrun AS, et al. Tumor classification by tissue microarray profiling: random forest clustering applied to renal cell carcinoma. Mod Pathol 2005;18:547-57.

93. Lunetta KL, Hayward LB, Segal J, et al. Screening large-scale association study data: exploiting interactions using random forests. BMC Genet 2004;5:32.

94. Liaw A, Wiener M. Classification and regression by randomForest. $R$ News 2002;2:18-22.

95. Neville PG. Controversy of variable importance in random forests J Unified Stat Tech 2013;1:15-20.

96. Breiman L, Cutler A. Manual-setting up, using, and understanding random forests V.4.0. Berkeley (CA): University of California,

Berkeley, 2003:33.

97. Storey JD. A direct approach to false discovery rates. J $R$ Stat Soc Ser B Stat Methodol 2002;64:479-98.

98. Dhamoon MS, Tai W, Boden-Albala B, et al. Risk of myocardial infarction or vascular death after first ischemic stroke: the Northern Manhattan Study. Stroke 2007:1752-8.
99. Touzé E, Varenne O, Chatellier G, et al. Risk of myocardial infarction and vascular death after transient ischemic attack and ischemic stroke: a systematic review and meta-analysis. Stroke 2005;36:2748-55. http://dx.doi.org/10.1161/01. STR.0000190118.02275.33

100. Tabrizchi R. Incidence of stroke after myocardial infarction. Vasc Health Risk Manag 2006:2:1-2.

101. Lichtman JH, Krumholz HM, Wang Y, et al. Risk and predictors of stroke after myocardial infarction among the elderly: results from the cooperative cardiovascular project. Circulation 2002;105:1082-7.

102. Loh E, Sutton MSJ, Wun C-CC, et al. Ventricular dysfunction and the risk of stroke after myocardial infarction. $N$ Engl $J$ Med 1997;336:251-7.

103. Association $\mathrm{AH}$. How cardiovascular \& stroke risks relate: American Stroke Association. 2014. http://www.strokeassociation.org/ STROKEORG/LifeAfterStroke/HealthyLivingAfterStroke/ UnderstandingRiskyConditions/How-Cardiovascular-StrokeRisks-Relate_UCM_310369_Article.jsp (accessed 26 Feb 2015).

104. Magnus $\mathrm{P}$, Beaglehole $\mathrm{R}$. The real contribution of the major risk factors to the coronary epidemics: time to end the "only-50\%" myth. Arch Intern Med 2001;161:2657-60.

105. Leander K, Hallqvist J, Reuterwall C, et al. Family history of coronary heart disease, a strong risk factor for myocardial infarction interacting with other cardiovascular risk factors: results from the Stockholm Heart Epidemiology Program (SHEEP). Epidemiology 2001;12:215-21.

106. Roncaglioni MC, Santoro L, D'Avanzo B, et al. Role of family history in patients with myocardial infarction. An Italian casecontrol study. GISSI-EFRIM Investigators. Circulation 1992;85:2065-72.

107. Gafarov VV, Gromova EA, Gafarova AV, et al. Myocardial infarction and stress at work place and in the family: 10-year risk of development in an open population of 2564-year-old men (epidemiological study in a framework of the WHO program MONICA-PSYCHOSOCIAL). Kardiologiia 2011;51: 10-16.

108. Chandola T, Brunner E, Marmot M. Chronic stress at work and the metabolic syndrome: prospective study. BMJ 2006;332:521-5

109. Kivimäki M, Leino-Arjas $\mathrm{P}$, Luukkonen $\mathrm{R}$, et al. Work stress and risk of cardiovascular mortality: prospective cohort study of industrial employees. BMJ 2002;325:857.

110. Stamler J, Daviglus ML, Garside DB, et al. Relationship of baseline serum cholesterol levels in 3 large cohorts of younger men to long-term coronary, cardiovascular, and all-cause mortality and to longevity. JAMA 2000;284:311-18.

111. Klag MJ, Ford DE, Mead LA, et al. Serum cholesterol in young men and subsequent cardiovascular disease. $N$ Engl $J$ Med 1993;328:313-18.

112. Anderson KM, Castelli WP, Levy D. Cholesterol and mortality. 30 years of follow-up from the Framingham study. JAMA 1987;257:2176-80.

113. Mukamal KJ, Chung $\mathrm{H}$, Jenny NS, et al. Alcohol consumption and risk of coronary heart disease in older adults: the Cardiovascular Health Study. J Am Geriatr Soc 2006:54:30-7.

114. Mukamal KJ, Kuller LH, Fitzpatrick AL, et al. Prospective study of alcohol consumption and risk of dementia in older adults. JAMA 2003;289:1405-13.

115. Abramson JL, Williams SA, Krumholz HM, et al. Moderate alcohol consumption and risk of heart failure among older persons. JAMA 2001;285:1971-7.

116. Manson JE, Colditz GA, Stampfer MJ, et al. A prospective study of maturity-onset diabetes mellitus and risk of coronary heart disease and stroke in women. Arch Intern Med 1991;151:1141-7.

117. Yokoyama H, Higuma T, Nishizaki F, et al. Abstract 16483: Marital status and long-term mortality of male patients presenting with acute myocardial infarction. Circulation 2014;130(Suppl 2): A16483-A83.

118. Kriegbaum M, Christensen U, Andersen PK, et al. Does the association between broken partnership and first time myocardial infarction vary with time after break-up? Int J Epidemiol 2013;42:1811-19.

119. Lammintausta A, Airaksinen JKE, Immonen-Räihä $P$, et al. Prognosis of acute coronary events is worse in patients living alone: the FINAMI myocardial infarction register. Eur J Prev Cardiol 2014;21:989-96

120. Hu B, Li W, Wang X, et al. Marital status, education, and risk of acute myocardial infarction in Mainland China: the INTER-HEART study. J Epidemiol 2012;22:123-9. 
121. Waltz M. Marital context and post-infarction quality of life: is it social support or something more? Soc Sci Med 1986;22:791-805.

122. Chandra V, Szklo M, Goldberg R, et al. The impact of marital status on survival after an acute myocardial infarction: a population-based study. Am J Epidemiol 1983;117:320-5.

123. Welin $\mathrm{C}$, Rosengren $\mathrm{A}$, Wedel $\mathrm{H}$, et al. Myocardial infarction in relation to work, family and life events. Cardiovasc Risk Factors 1995;5:30-8.

124. Eaker ED, Pinsky J, Castelli WP. Myocardial infarction and coronary death among women: psychosocial predictors from a 20-year follow-up of women in the Framingham study. Am $J$ Epidemiol 1992;135:854-64.

125. Lanas F, Avezum A, Bautista LE, et al. Risk factors for acute myocardial infarction in Latin America: the INTERHEART Latin American study. Circulation 2007:115:1067-74.

126. Welin C, Lappas G, Wilhelmsen L. Independent importance of psychosocial factors for prognosis after myocardial infarction. J Intern Med 2000;247:629-39.

127. Brezinka V, Kittel F. Psychosocial factors of coronary heart disease in women: a review. Soc Sci Med 1996;42:1351-65.

128. Juutilainen $\mathrm{A}$, Lehto $\mathrm{S}$, Ronnemaa $\mathrm{T}$, et al. Type 2 diabetes as a "coronary heart disease equivalent": an 18-year prospective population-based study in Finnish subjects. Diabetes Care 2005;28:2901-7.

129. Hu FB, Stampfer MJ, Solomon CG, et al. The impact of diabetes mellitus on mortality from all causes and coronary heart disease in women: 20 years of follow-up. Arch Intern Med 2001;161: 1717-23.

130. Haffner SM, Lehto S, Rönnemaa T, et al. Mortality from coronary heart disease in subjects with type 2 diabetes and in nondiabetic subjects with and without prior myocardial infarction. N Engl J Med 1998;339:229-34.

131. Parker WH, Feskanich D, Broder MS, et al. Long-term mortality associated with oophorectomy compared with ovarian conservation in the nurses' health study. Obstet Gynecol 2013;121:709-16.

132. Wellons M, Ouyang P, Schreiner PJ, et al. Early menopause predicts future coronary heart disease and stroke: the multi-ethnic study of atherosclerosis. Menopause 2012;19:1081-7.

133. Ingelsson $\mathrm{E}$, Lundholm $\mathrm{C}$, Johansson $\mathrm{AL}$, et al. Hysterectomy and risk of cardiovascular disease: a population-based cohort study. Eur Heart J 2011;32:745-50.

134. Parker WH, Broder MS, Chang E, et al. Ovarian conservation at the time of hysterectomy and long-term health outcomes in the nurses' health study. Obstet Gynecol 2009;113:1027-37.

135. Dørum A, Tonstad S, Liavaag AH, et al. Bilateral oophorectomy before 50 years of age is significantly associated with the metabolic syndrome and Framingham risk score: a controlled, populationbased study (HUNT-2). Gynecol Oncol 2008;109:377-83.

136. Lobo RA. Surgical menopause and cardiovascular risks. Menopause 2007;14(Pt 2):562-6.

137. Simon T, Mary-Krause M, Cambou JP, et al. Impact of age and gender on in-hospital and late mortality after acute myocardial infarction: increased early risk in younger women: results from the French nation-wide USIC registries. Eur Heart J 2006;27:1282-8.

138. Falkeborn M, Schairer C, Naessén T, et al. Risk of myocardial infarction after oophorectomy and hysterectomy. J Clin Epidemiol 2000;53:832-7.

139. Stampfer MJ, Colditz GA, Willett WC. Menopause and heart disease. Ann N Y Acad Sci 1990;592:193-203.

140. Colditz GA, Willett WC, Stampfer MJ, et al. Menopause and the risk of coronary heart disease in women. $N$ Engl $J$ Med 1987;316:1105-10.
141. Rosenberg L, Hennekens $\mathrm{CH}$, Rosner B, et al. Early menopause and the risk of myocardial infarction. Am J Obstet Gynecol 1981;139:47-51

142. Yonker JA, Chang V, Roetker NS, et al. Hypothalamic-pituitarygonadal axis homeostasis predicts longevity. Age 2013;35: 129-38.

143. Schierbeck LL, Rejnmark L, Tofteng CL, et al. Effect of hormone replacement therapy on cardiovascular events in recently postmenopausal women: randomised trial. BMJ 2012;345: e6409.

144. Falkeborn M, Persson I, Adami HO, et al. The risk of acute myocardial infarction after oestrogen and oestrogen-progestogen replacement. Br J Obstet Gynaecol 1992;99:821-8.

145. Jia EZ, Xu ZX, Guo CY, et al. Renin-angiotensin-aldosterone system gene polymorphisms and coronary artery disease: detection of gene-gene and gene-environment interactions. Cell Physiol Biochem 2012;29:443-52.

146. Oki K, Yamane K, Satoh K, et al. Aldosterone synthase (CYP11B2) $\mathrm{C}$-344T polymorphism affects the association of age-related changes of the serum C-reactive protein. Hypertens Res 2010;33:326-30.

147. Kumar NN, Benjafield AV, Lin RCY, et al. Haplotype analysis of aldosterone synthase gene (CYP11B2) polymorphisms shows association with essential hypertension. $J$ Hypertens 2003;21:1331-7.

148. Tsukada K, Ishimitsu T, Teranishi M, et al. Positive association of CYP11B2 gene polymorphism with genetic predisposition to essential hypertension. J Hum Hypertens 2002;16: 789-93.

149. Tamaki S, Iwai N, Tsujita $\mathrm{Y}$, et al. Genetic Polymorphism of CYP11B2 Gene and Hypertension in Japanese. Hypertension 1999;33:266-70.

150. Gigante B, Bennet AM, Leander K, et al. The interaction between coagulation factor 2 receptor and interleukin 6 haplotypes increases the risk of myocardial infarction in men. PLOS One 2010;5:e11300.

151. Liu Y, Berthier-Schaad Y, Fallin MD, et al. IL-6 Haplotypes, inflammation, and risk for cardiovascular disease in a multiethnic dialysis cohort. J Am Soc Nephrol 2006;17: 863-70.

152. Bennet AM, Prince JA, Fei GZ, et al. Interleukin-6 serum levels and genotypes influence the risk for myocardial infarction. Atherosclerosis 2003;171:359-67.

153. Borzyszkowska J, Stanislawska-Sachadyn A, Wirtwein M, et al. Angiotensin converting enzyme gene polymorphism is associated with severity of coronary artery disease in men with high total cholesterol levels. J Appl Genet 2012;53:175-82.

154. Mishra A, Srivastava A, Mittal T, et al. Impact of renin-angiotensinaldosterone system gene polymorphisms on left ventricular dysfunction in coronary artery disease patients. Dis Markers 2012;32:33-41.

155. Patel S, Steeds R, Channer K, et al. Analysis of promoter region polymorphism in the aldosterone synthase gene (CYP11B2) as a risk factor for myocardial infarction. Am J Hypertens 2000;13:134-9.

156. Bis JC, Heckbert SR, Smith NL, et al. Variation in inflammationrelated genes and risk of incident nonfatal myocardial infarction or ischemic stroke. Atherosclerosis 2008;198:166-73.

157. Rosamond WD, Sprafka JM, McGovern PG, et al. Validation of self-reported history of acute myocardial infarction: experience of the Minnesota Heart Survey Registry. Epidemiology 1995;6: 67-9. 